\title{
Automated Location Detection of Retention and Detention Basins for Water Management
}

\author{
Sonja Teschemacher *(D), Daniel Bittner $(\mathbb{D}$ and Markus Disse \\ Chair of Hydrology and River Basin Management, Technical University of Munich, 80333 Munich, Germany; \\ daniel.bittner@tum.de (D.B.); markus.disse@tum.de (M.D.) \\ * Correspondence: sonja.teschemacher@tum.de
}

Received: 21 April 2020; Accepted: 21 May 2020; Published: 23 May 2020

\begin{abstract}
Retention and detention basins are engineering constructions with multiple objectives; e.g., flood protection and irrigation. Their performance is highly location-dependent, and thus, optimization strategies are needed. LOCASIN (Location detection of retention and detention basins) is an open-source MATLAB tool that enables automated and rapid detection, characterization and evaluation of basin locations. The site detection is based on a numerical raster analysis to determine the optimal dam axis orientation, the dam geometry and the basin area and volume. After selecting a reasonable basin combination, the results are summarized and visualized. LOCASIN represents a user-friendly and flexible tool for policy makers, engineers and scientists to determine dam and basin properties of optimized positions for planning and research purposes. It can be applied in an automated way to solve small and large scale engineering problems. The software is available on GitHub.
\end{abstract}

Keywords: reservoir characterization; topographic analysis; optimization approach; engineering application; water management; open-source code; Matlab

\section{Introduction}

Open source and user-friendly modeling and analysis tools play vital roles for engineers and decision-makers in water management [1,2]. In particular, the development of analysis tools for the management of floods and droughts is an important topic hydrologists are continuously dealing with [3,4]. Generally, one focus in flood management is the retention of water in a catchment for a defined period of time in order to reduce flood peaks and related hazards [5]. In contrast, the management of droughts requires having a source of stored water which can be used to meet the water demand in a region affected by a water shortage [6].

Despite having different main objectives, the management of floods and that of droughts have in common that the retention of water plays an important role. Depending on the size and specific characteristics of a catchment of interest, decision-makers may favor different sizes of detention basins, retention basins or reservoirs (from now on called basin). While large basins may be more appropriate as a flood protection measure for entire river catchments $[7,8]$, small decentralized basins can play a supportive role in flood management for smaller subcatchments $[9,10]$. Similarly, those small basins or reservoirs have been shown to be effective in providing water for irrigation [11] or when being used for managed aquifer recharge [12]. Finding appropriate positions for all kinds of basins or reservoirs in a catchment independently from their respective size is an important task in water management for which specific and objective-oriented tools are needed. So far, different tools were proposed that were designed to find locations for flood detention basins [13-18], or for the optimization of irrigation reservoirs [19,20] or to select sites for managed aquifer recharge [21,22]. However, the level of detail of the results is often not appropriate for the evaluation of small basins, and the degree of automation 
could be improved in order to be applied for large-scale problems. Many studies analyze and evaluate spatial catchment characteristics such as land use, slope or geomorphology in order to determine suitable regions for the positioning of basins [13-15,18,21]. The local topography and the resulting dam or basin geometry are not covered in these analyses. Wimmer et al. [17] present a methodology for the automated determination of basin locations and characteristics based on an analysis of contour lines. However, they do not include an evaluation based on constructional, economic or legal criteria. The tool DamSite [16,23] allows a determination of possible basin sites under consideration of the retention volume as well as the resulting costs and accordingly combines the two approaches mentioned above. This tool uses results of the catchment deliniation to estimate the dam orientation and geometry. While this simplified approach is sufficient for the scale applied by Petheram et al. [16], it cannot be transferred to very small basins. Moreover, to the best of our knowledge, one single and integrated approach that can be used to identify appropriate basin locations for different water management objectives like flood mitigation, irrigation or managed aquifer recharge is not in existence.

In this work, we want to contribute to this identified gap by developing an automated tool that enables detecting appropriate locations for basins of variable sizes for a wide range of spatial scales based on user-defined criteria. A flexible consideration of different raster input data for the evaluation of basin sites with different raster widths allows an optimization of the sites for different objectives. Moreover, it can be used to describe dam and basin geometries for very small basins with sufficient accuracy. The detection is primarily based on identifying valley types and depressions in a landscape which may be used as basins considering small dam lengths. Moreover, additional information can be added to exclude or to favor different basin locations; e.g., land use types or the proximity to settlements. LOCASIN has a modular structure containing codes for preprocessing, analysis of dam positions, basin analysis, selection of basin combinations and postprocessing, which are described in Sections 2 and 3. Section 4 provides a case study with four application examples with further information in Appendix A and a step-by-step manual in Appendix B. A summary of this work is given in Section 5 .

\section{Methodology}

The methodology section follows the structure of the program code developed with MATLAB R2018b and comprises five parts, which are executed consecutively (Figure 1). The preprocessing result is a list of all candidate dam sites (Figure 1, Step 1). The sites are analyzed with respect to the dam positioning (Figure 1, Step 2) and the basin characteristics (Figure 1, Step 3). If sites are inappropriate for the defined criteria, they are excluded for further analyses and assigned to a specific exit code (Table 1) to allow for the plausibility check of the procedure. The resulting dam sites are evaluated to automatically select a reasonable combination of basins (Figure 1, Step 4) and provide a description of the relations between water depth, storage and area. The postprocessing step includes a summary and a visual representation of the results (Figure 1, Step 5). Several examples following these five steps are provided in the case study (Section 4) and the tutorial in Appendix B.

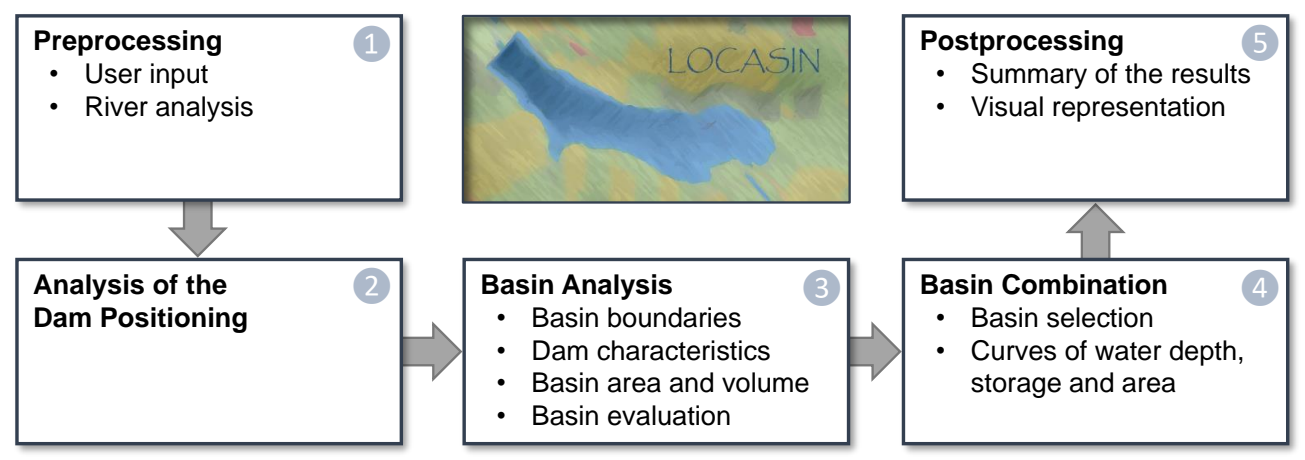

Figure 1. Conceptual sketch of the program structure. 


\subsection{Preprocessing}

The required data for the analysis of candidate dam sites are defined and imported in the preprocessing step. The user input (Section 2.1.1) describes the input data, the dam and the basin characteristics. The data are imported, structured and analyzed in the river analysis function (Section 2.1.2).

\subsubsection{User Input}

The user input contains mandatory and optional spatial input data (Table 2) and parameters to define the dam and basin characteristics and saving and plotting options (Table 3).

The spatial input data are imported from ascii raster files and have to have the same extent and resolution. The required grids are essential for the topographic analysis of potential dam and basin sites, while the optional grids are used to evaluate dam and basin sites and can be defined flexibly. The parameters in Table 3 comprise the limits for the dam and basin dimensions; the characteristics of the dam geometry; the level of detail of the basin analyses; the weighting factors of the objective function; and debug, save and plotting options. Accordingly, they are decisive for the characteristics of the basin sites. A more detailed description of the input data is presented in Section 3.2.

\subsubsection{River Analysis}

In the river analysis section, the mandatory input data are imported and analyzed to define river cells based on the flow accumulation grid and the predefined threshold value thresh. The resulting river points are characterized with regard to their IDs, locations, elevation levels, upstream and downstream neighboring river point IDs and the exit codes (Table 1). The required data for this analysis are the DEM and the flow direction grid. Finally, the river points are evaluated with respect to their locations. That implies that river points which are too close to the borders or which are located in restricted areas (e.g., within settlements) are excluded from the potential dam sites and the following analyses.

\subsection{Analysis of the Dam Positioning}

The evaluation of the best dam axis orientation in the valley is performed for all potential dam sites separately. The DEM is clipped for the analyses with respect to the river point and the predefined maximum dam length to save computational costs. The procedure to determine the dam positioning is based on three criteria:

1. The dam axis has to be an almost straight line through the respective river point.

2. The orientation of the dam axis has to be the shortest waylength to close the valley.

3. The elevation at the boundaries of the clipped DEM in extension of the dam axis has to be above the dam crest.

The bases for the analysis are multiple generated raster datasets, which are intersected in order to establish potential dam orientations. These include the distance of any raster cell to the river point, the angles of the line to the river point in horizontal and vertical directions and a separation of the cells in the east and west to guarantee a positioning of the dam endpoints at opposing sides of the river point. Furthermore, the shoreline for the potential water level is determined and evaluated regarding the elevation in extension of the dam. The selected final dam axis is the shortest linkage of two points on the shoreline, which fulfills the conditions of the angles, and thus, defines a straight line through the river point.

The shoreline is defined by the potential maximum dam height. If no possible dam axis can be determined, an iterative extension of the clipped DEM is performed, which is followed by a consecutive reduction of the dam height by the distance until a dam axis is found or the minimum dam height is reached. Thus, both variables largely influence the computational power needed. A reduction of the 
computation time can be achieved through an increase of the variable neighbors_exclude_distance, which results in the exclusion of neighboring river points of a dam location within a specific distance.

\subsection{Basin Analysis}

The analysis of potential basins is performed consecutively for all possible dam locations and is separated in four steps. If a site does not fulfill the predefined criteria, it is excluded after the respective step (Table 1).

\subsubsection{Basin Boundaries}

The purpose of the first step is to determine the approximate extent of a potential basin area, which is necessary to clip the DEM, and consequently, to reduce the main memory requirements of the following steps. The extent is estimated by including all points, which may be within the basin. These comprise all upstream neighbors of the dam river point with an elevation below the dam crest elevation. Additionally, the endpoints of potential dams at these neighboring points are considered. It may happen that no river points having an elevation above the dam crest can be found within the total extent of the analyzed DEM. In this case, the dam crest elevation is set to the elevation of the highest upstream neighbor, where the resulting dam height needs to be within the predefined range.

\subsubsection{Dam Characteristics}

The dam characteristics and its geometry are decisive for the economical evaluation of a basin, and thus, are considered in detail. The geometry of the dams is described by four parameters: the elevation of the dam crest, the dam axis orientation (Section 2.2), the width of the dam crest and the dam slopes perpendicular to the dam axis. The elevation of the dam crest is defined by the river point elevation and the maximum dam height, which may have been reduced from the predefined value in Section 2.3.1.

The basis to build the dam surface is the dam axis orientation. In a first step, the line representing the dam axis is extrapolated to the borders of the clipped basin-DEM (Section 2.3.1). Next, the dam is widened and the surface elevation is recorded for every point on the dam for the predefined potential dam heights (steps from dam_height_max to dam_height_min by distances of dam_dist_eval). The result represents the surface elevations of dams with different maximum heights. The final dam geometry is obtained by subtracting the dam surface and the DEM. Every potential dam is described by its height, its volume and its dam axis length.

\subsubsection{Basin Area and Volume}

The potential efficiency of a basin is usually evaluated with respect to its storage volume. The determination of the basin volume and area is the final step in the description of a potential dam site. The analysis is based on the intersection of the clipped DEM (Section 2.3.1) and the surface elevations for all potential dam heights (Section 2.3.2), resulting in the shorelines of potential basins. The basin area of the maximum dam height is determined with a river point upstream of the dam point. This point lies within the respective shoreline, and thus, defines which side of the shoreline is water. As a consequence, the inundation areas for the smaller dam heights equal the reduced maximum basin area based on the DEM-surface elevation-intersection. The flooded areas and the respective storage volumes are calculated for all potential dam heights. The storage volume is additionally determined for a wall geometry of the dam to quantify the storage volume that is lost due to the slopes of a realistic dam geometry.

\subsubsection{Basin Evaluation}

The last step of the basin analysis is an evaluation of all potential dam heights and the respective basins for each site. The selection of the best dam for a respective site is based on user-defined 
weighting factors. At the beginning of the evaluation, the potential dam heights are checked with regard to predefined criteria. These include the ranges of the dam height, the dam length, the basin volume and the specific volume. Furthermore, the number of restricted cells in the flooded area is determined and compared to its respective threshold values. If all potential dam heights are excluded, the site is rejected. The selection of the ideal dam height is based on an objective function (Equation (2)), which includes four criteria to compare the dam and basin characteristics with one another:

- Criterion 1: dam volume per basin volume $\left(\mathrm{m}^{3} / \mathrm{m}^{3}\right)$.

- Criterion 2: basin area per basin volume $(1 / \mathrm{m})$.

- Criterion 3: share of well-suited cells in the basin area (-) (Section 3.2).

- Criterion 4: share of not-suited cells in the basin area (-) (Section 3.2).

In order to combine the criteria, a scaling of the individual criteria between zero and one is performed, where the optimum of the resulting dimensionless parameters $C_{1}$ to $C_{4}$ is one.

$$
C_{x}= \begin{cases}1-\frac{\operatorname{criterion} x-\min (\operatorname{criterion} x)}{\max (\operatorname{criterion} x)-\min (\operatorname{criterion} x)}, & \text { where } x=1,2,4 \\ \frac{\operatorname{criterion} x-\min (\operatorname{criterion} x)}{\max (\operatorname{criterion} x)-\min (\operatorname{criterion} x)}, & \text { where } x=3\end{cases}
$$

The respective weighting factors are defined by the user (Section 3.2). The factors $w_{1}$ to $w_{4}$ are adapted to ensure that their sum equals one. Thus, the value of the objective function $f$ ranges between zero and one with its optimum at the upper limit.

$$
f=w_{1} \times C_{1}+w_{2} \times C_{2}+w_{3} \times C_{3}+w_{4} \times C_{4}
$$

The optimum dam height of every site is characterized by the maximum value of the objective function. It is picked for the following selection procedure.

\subsection{Basin Combination}

The resulting basins from the previous analysis include all potential dam sites. However, the dam and basin areas of the different sites are overlapping, which implies that not all of them can be included in the same basin combination. Thus, an assorting of the basins is required based on their suitability.

\subsubsection{Basin Selection}

The selection of the basin combination is based on the same objective function and criteria which were described in Section 2.3.4. The scaling procedure of the four criteria to determine the parameters $C_{1}$ to $C_{4}$ comprises the best dam heights of all possible dam locations. The basins of the final combination are chosen in an iterative procedure: The first basin is the one with the largest objective function value. Consequently, all overlapping basins are deleted from the database, which brings the second-best basin to the top of the list. Again, this basin is chosen and overlapping basins are deleted, and so forth. The final result is a combination of basins which do not interfere with one another.

\subsubsection{Curves of the Basin Depth, Volume and Area}

The characteristics of a basin depend on the relationship between water depth, storage volume and flooded area. Hence, the respective curves are determined for the dam geometry and for the wall geometry. The number of sampling points is defined by the variable discretization_number. The results can be used, e.g., as input data for estimating the efficiency of a basin with a hydrological model [10]. 


\subsection{Postprocessing}

The postprocessing section includes the summary, storage and visual representation of the results.

\subsubsection{Summary of the Results}

The results contain information about the analysis process, the characteristics of all possible dam sites and the dams of the selected combination. The required level of detail depends on further planned applications; e.g., the visualization of the results (Section 2.5.2) or hydrological efficiency estimations of basin combinations. A detailed description of the output data is given in Section 3.3.

\subsubsection{Visual Representation}

The summarized output data can be analyzed and visualized in multiple ways. The included visual representation comprises six figures: 1 and 2 give an overview on the results (Figure 2a) and the sorting procedure (Figure 2b). 3 and 4 characterize the single basins on a double-sided fact sheet (Figure 3). 5 and 6 allow one to compare the dam sites (not shown). The figures are taken from one of the examples of the case study.

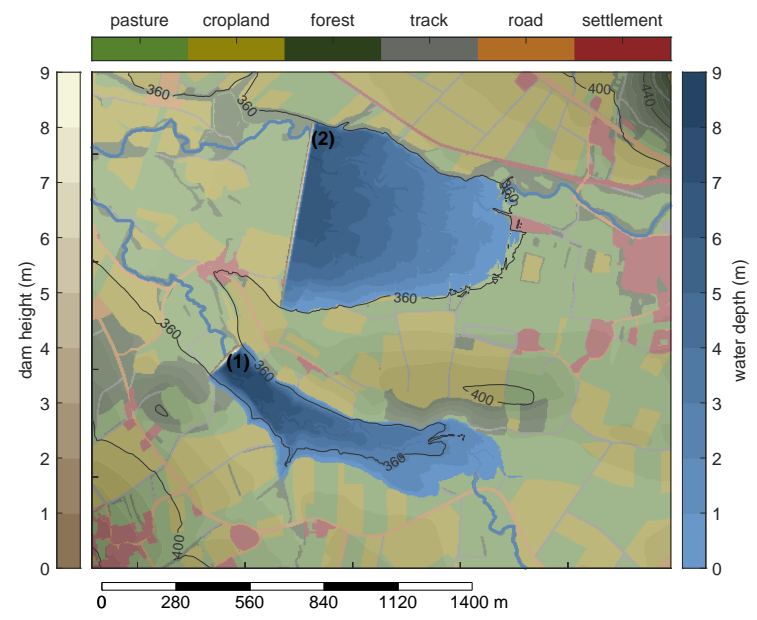

(a) Selected basin combination.

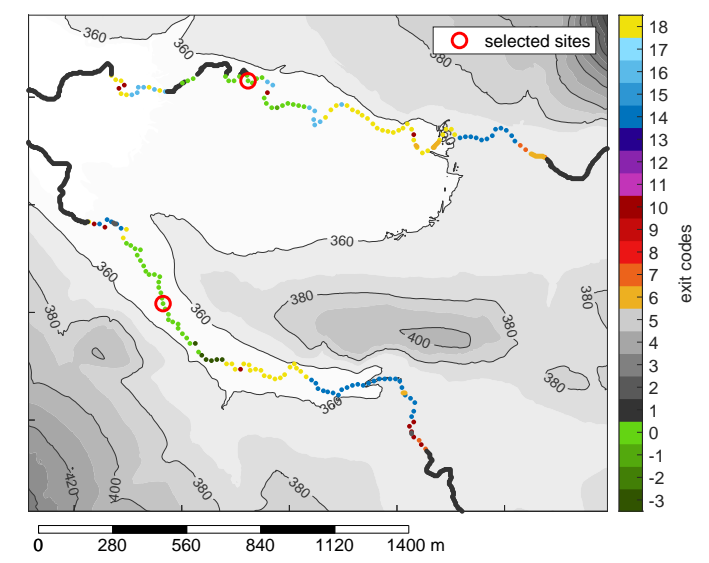

(b) River network with exit codes (Table 1).

Figure 2. Spatial distribution of potential dam sites and selected basin locations.

While the first page of the fact sheet (Figure 3a) shows the characteristics of the basin for the selected dam height, the second page (Figure $3 \mathrm{~b}$ ) allows one to understand the selection and to examine alternatives. The variable dam height in this illustration corresponds to the dam height at the location of the river, whereas the term dam height (real) indicates the maximum dam height of the entire dam structure. The marked possible dam heights represent dam heights for which the corresponding basins meet the criteria defined by the user and thus could potentially be implemented. In this test case, for example, the maximum number of unsuitable cells within a basin area causes the maximum value of the target function not to be selected. The different curves can be used to evaluate the properties at alternative dam heights and to adjust the limits if necessary. 


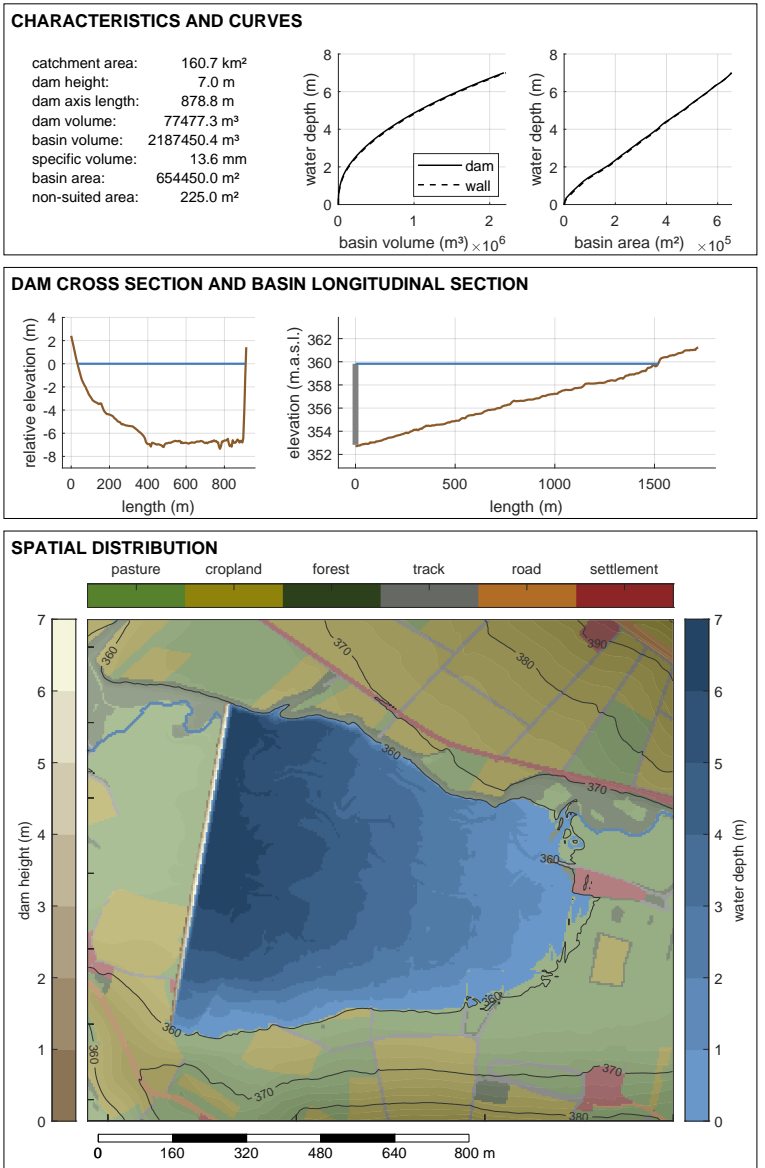

(a)
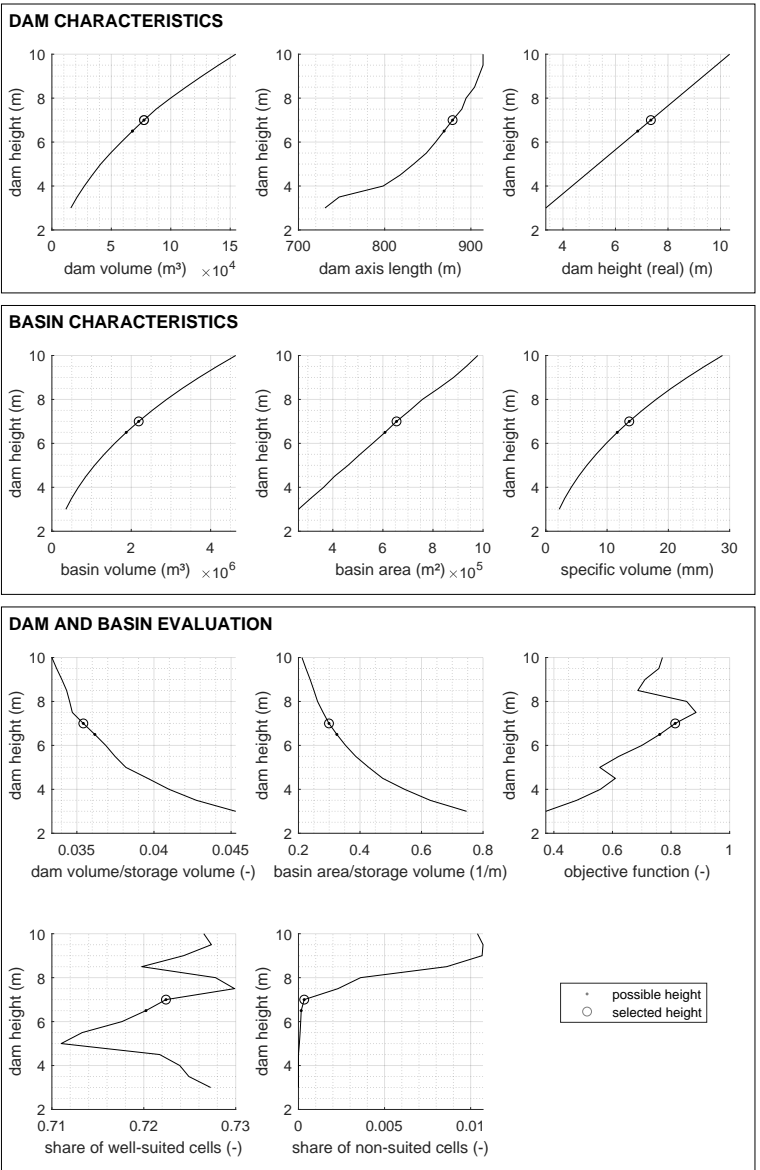

(b)

Figure 3. Fact sheet of one exemplary basin. (a) Information on the selected basin: (1) curves of the water depths, the storage volume and the flooding area; (2) dam cross-section and basin longitudinal section; (3) topview of the basin. (b) Information on all potential dam heights: (1) dam characteristics; (2) basin characteristics; (3) dam and basin evaluation criteria.

\section{Code Structure and Data Definitions}

The general procedure of the analyses is explained in Section 2, whereas the following paragraphs comprise technical aspects of the code structure and a more detailed description of the input data and output data.

\subsection{Code Structure}

The program structure, including the single functions' names and the references to the methodology section, is illustrated in Figure 4. The variables, which can be adapted by the user, are summarized in the function USER_INPUT.m. Alternatively, the specified data can be defined in an Excel-table, which is imported and allocated by the function USER_INPUT_from_xlsx.m. The parameters are specified in Section 3.2. They include required and optional spatial input data (Table 2) and parameters to define dam and basin characteristics and saving and plotting options. The functions listed in Figure 4 are run consecutively for each potential site. If a dam or basin with the user-defined properties is not possible at the particular location, the respective exit_code is adjusted (Table 1). Positive exit_codes lead to an exclusion of the location for further analyses, whereas negative exit_codes only indicate a reduction in the target dam height. 
LOCASIN.m

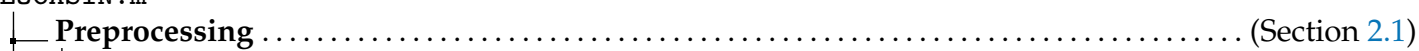

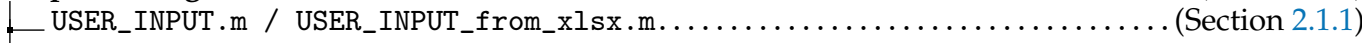

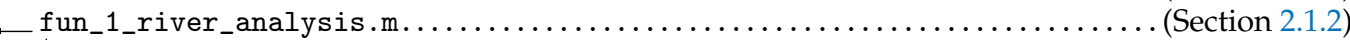
L_un_1n1_ASCIimport.m

Analysis of the Dam Positioning.

(Section 2.2)

I fun_2_determine_shortest_dam.m

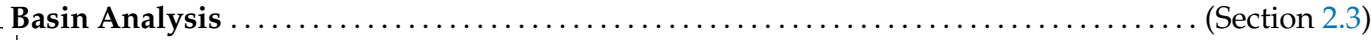

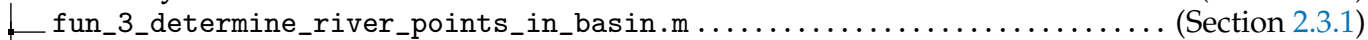

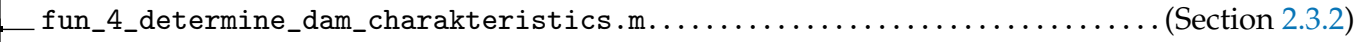

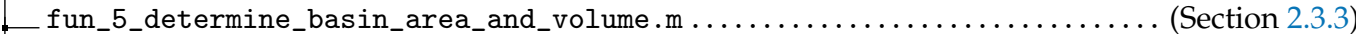

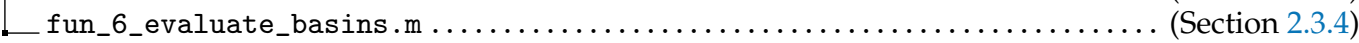

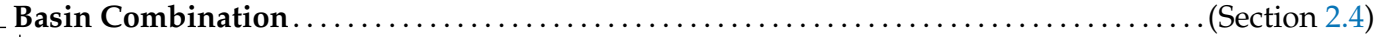

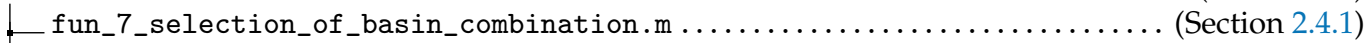

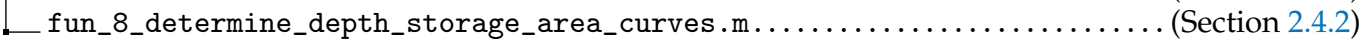

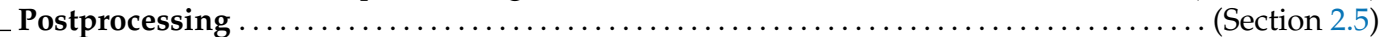

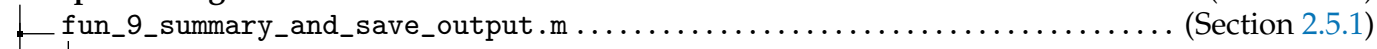

Lfun_9n1_save_basins_as_ascii.m

_fun_9n2_save_basins_characteristics_as_xlsx.m

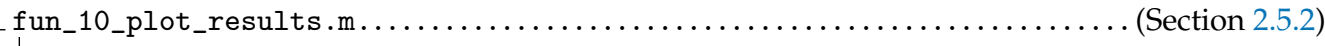

_. plot_1_spatial_exit_codes.m

_. plot_2_spatial_all_basins.m

- plot_3_single_basin_characteristics.m

[_plot_3n1_spatial_basin.m

_plot_3n2_updateContours.m

plot_4_potential_dam_characteristics_portrait.m

plot_5_curves_depth_storage_area.m

Figure 4. Code structure of LOCASIN.

Table 1. Exit codes and definitions; exit codes $>0$ : excluded sites, exit codes $\leq 0$ : considered sites.

\begin{tabular}{c|l}
\hline fun_1_river_analysis.m \\
\hline 1 & river point is too close to the grid border or excluded by user defined spatial data for dam restrictions \\
2 & river point is excluded by user defined spatial data for basin restrictions (e.g., land use) \\
3 & target basin volume is too small for the target specific volume (=too large rivers are excluded) \\
4 & target basin volume is too large for the target specific volume (=too small rivers are excluded) \\
\hline fun_2_determine_shortest_dam.m \\
\hline 5 & river point is excluded for further analysis, because a potential dam exists within a predefined distance \\
6 & no possible dam orientation available to close the valley (with the defined dam length) \\
-1 & dam height had to be reduced to close the valley (with the defined dam length) \\
\hline fun_3_determine_river_points_in_basin.m \\
\hline 7 & no basin endpoint exists (river point) for the minimum dam height \\
-2 & dam height had to be reduced, because the basin endpoint could be found within the extent of the DEM \\
\hline fun_5_determine_basin_area_and_volume.m \\
\hline 8 & no upstream river point available for the basin area analysis \\
9 & no basin due to an erroneous dam orientation \\
10 & basin area touches the borders (usually occurs, if the dam does not close the valley totally) \\
-3 & dam height had to be reduced, because the basin touched the borders of the DEM \\
\hline fun_6_evaluate_basins.m \\
\hline 11 & points of the dam axis or the whole dam are higher than the defined maximum dam height \\
12 & maximum dam height smaller than the defined minimum dam height (dam_height_min) \\
13 & dam axis is longer than the defined maximum dam length (dam_length_max) \\
14 & basin volumes smaller than the defined minimum basin volume (basin_volume_min) \\
15 & basin volumes larger than the defined maximum basin volume (basin_volume_max) \\
16 & specific volume of the basin is smaller than the defined minimum specific volume (sV_min) \\
17 & specific volume of the basin is larger than the defined maximum specific volume (sV_max) \\
18 & too many exclusion-cells in the basin \\
\hline
\end{tabular}

\subsection{Input Data}

The spatial input data (Table 2) is the basis for the analyses (required grids) and site evaluations (optional grids). The required grids include a digital elevation model (DEM) and grids with flow 
direction and flow accumulation information. The pit-filled DEM can optionally be considered for the visualization of the basin cross-section and longitudinal section. The coordinate ranges are also optional parameters, which can be defined to extract a subarea of a larger grid, and thus, reduce the main memory requirements during the actual analysis. Further optional grids can be assigned to the structure arrays info_exclude_dam and info_exclude_basin: the structure array info_exclude_dam is applied to analyze potential dam positions, whereas info_exclude_basin is used for basin and dam areas. The first parameter is used to exclude certain dam points already at the beginning of the analyses, and thus, save calculation time. The aim of the second parameter is to evaluate the influenced area of the combination of dam and basin after the analyses are completed. The field names ( $f i e l d$ ) of both structure arrays are customizable (e.g., river_buffer, landuse, geology, conductivity) and thus can contain various data, allowing the input data for the evaluation of the sites to be individually selected and extended. In contrast, the second order fields (column field in Table 2) require predefined names (e.g., name, exclude, include; Table 2). These fields contain user-defined numbers, which are used to exclude specific sites or to rank the suitability of basins. Basins for which the areas that are described with the parameter exclude exceed the specified limit exclude_threshold are not considered in the results. In contrast, the ranking of the basins is based on the fields well_suited and not_suited, in which for instance land use numbers can be defined that are well suited for a basin location (e.g., grassland) or not suited for a basin location (e.g., settlement areas). e.g., the inclusion of settlement areas in the exclude and not_suited variables leads to a reduction of the corresponding factor of the objective function $\left(C_{4}\right.$, Equation (2)). In case the value of exclude_threshold is exceeded, e.g., when having a higher dam heigth, the corresponding basin of this dam height is excluded accordingly.

Table 2. Required and optional spatial input data.

\begin{tabular}{|c|c|c|}
\hline Structure Array & Field & Definition \\
\hline grids_required. & $\begin{array}{l}\text { dem } \\
\text { dir } \\
\text { acc } \\
\text { dem_fill } \\
\text { x_range / y_range } \\
\end{array}$ & $\begin{array}{l}\text { digital elevation model } \\
\text { flow directions } \\
\text { flow accumulation sum } \\
\text { pit-filled DEM (optional) } \\
\text { coordinate area to be analyzed }\end{array}$ \\
\hline $\begin{array}{l}\text { info_exclude_dam. } \\
(\text { field). }\end{array}$ & $\begin{array}{l}\text { name } \\
\text { exclude } \\
\text { include }\end{array}$ & $\begin{array}{l}\text { file name of spatial data to evaluate dam locations } \\
\text { array with numbers, which are excluded (all others are included) } \\
\text { array with numbers, which are included (all others are excluded) }\end{array}$ \\
\hline $\begin{array}{l}\text { info_exclude_basin. } \\
(\text { field). }\end{array}$ & $\begin{array}{l}\text { name } \\
\text { exclude } \\
\text { exclude_threshold } \\
\text { include } \\
\text { well_suited } \\
\text { not_suited }\end{array}$ & $\begin{array}{l}\text { file name of spatial data to evaluate dam and basin locations } \\
\text { array with numbers, which are excluded (all others are included) } \\
\text { threshold value for the maximum number of cells of one exclude } \\
\text { group in one basin (several groups and thresholds can be defined } \\
\text { to distinguish between different factors, e.g., settlements } \\
\text { and forest) } \\
\text { array with numbers, which are included (all others are excluded) } \\
\text { array with numbers, which are well suited for basin locations } \\
\text { array with numbers, which not suited for basin locations }\end{array}$ \\
\hline
\end{tabular}

The user-defined parameters in Table 3 are subdivided into seven groups. The first group describes the limits for the dam and basin extents. Potential dams or basins beyond these values are excluded. The second group defines the characteristics of the dam structure. The respective parameters do not influence the feasibility of implementing a dam site, but its (economic) suitability. The third group affects the level of detail of the basin detection procedure. The values are decisive for the number of investigated dam positions, the number of potential dam heights and the accuracy of the output curves. Thus, they affect the computational effort; i.e., computation time and main memory requirements. The fourth group are weighting factors of the objective function to favor specific basin locations (Equation (2)). The save and debug options are for analysis purposes; With the debugging-option, intermediate stages of the analyses can be plotted to understand and assess the site-selection process. The save options define the level of detail of the saved output data. The requirements are user-specific 
and depend on the purpose for which the results are needed. The plotting options define the way how results are visualized. The figures can also be plotted separately with the LOCASINplotting tool using already saved results. The variable raster_selected defines the background map for the spatial overview of the results.

Table 3. Parameters to define dam and basin characteristics, and running, saving and plotting options.

\begin{tabular}{|c|c|}
\hline Variable Name & Definition \\
\hline dam_height_max & maximum dam height (m, whole dam) \\
\hline dam_height_min & minimum dam height ( $\mathrm{m}$, at the highest position) \\
\hline dam_height_buffer & dam height buffer value for the exclusion of dams (m) \\
\hline dam_length_max & maximum length of the dam axis (m) \\
\hline exclude_longer_dams & definition if the dam length is a restriction parameter (yes/no: $1 / 0$ ) \\
\hline basin_volume_max & maximum storage volume of the basin $\left(\mathrm{m}^{3}\right)$ \\
\hline basin_volume_min & minimum storage volume of the basin $\left(\mathrm{m}^{3}\right)$ \\
\hline sV_min & minimum specific volume (mm, optional parameter) \\
\hline sV_max & maximum specific volume (mm, optional parameter) \\
\hline $\begin{array}{l}\text { dam_slope_m } \\
\text { dam_crest_width }\end{array}$ & $\begin{array}{l}\text { slope angle: horizontal length } \mathrm{m} \text { per } 1 \mathrm{~m} \text { height difference } \\
\text { width of the dam crest }(\mathrm{m})\end{array}$ \\
\hline thresh & $\begin{array}{l}\text { threshold for the accumulation grid to define rivers (optional if } \mathrm{sV}_{-} \text {max is } \\
\text { defined) }\end{array}$ \\
\hline $\begin{array}{l}\text { limit_dam_height } \\
\text { dam_dist_eval }\end{array}$ & $\begin{array}{l}\text { dam_height_max is (1): valid for the whole dam; (2): only valid for the dam axis } \\
\text { evaluation step size between dam_height_min and dam_height_max }(\mathrm{m})\end{array}$ \\
\hline discretization_number & $\begin{array}{l}\text { discretization of the curves for impounding heights, storage volumes and basin } \\
\text { areas (number of points) }\end{array}$ \\
\hline $\begin{array}{l}\text { neighbors_exclude } \\
\text { _distance }\end{array}$ & $\begin{array}{l}\text { distance in which neighboring river points are excluded for further analysis after } \\
\text { a dam location has been determined }(\mathrm{m})\end{array}$ \\
\hline $\begin{array}{l}\text { w1_damVolume_per } \\
\text { _basinVolume }\end{array}$ & weighting factor for criterion 1 (dam volume per basin volume) \\
\hline w2_basinArea_per & weighting factor for criterion 2 (basin area per basin volume) \\
\hline _basinVolume & \\
\hline w3_share_well_suited & weighting factor for criterion 3 (share of well-suited cells) \\
\hline w4_share_not_suited & weighting factor for criterion 4 (share of not-suited cells) \\
\hline $\begin{array}{l}\text { debug_on } \\
\text { save_memory }\end{array}$ & $\begin{array}{l}\text { debugging option to assess the analysis process }(\text { activate }=1 \text {, deactivate }=2) \\
\text { definition if inappropriate dam sites are deleted immediately to reduce main } \\
\text { memory requirements (yes } / \text { no: } 1 / 0 \text { ) }\end{array}$ \\
\hline $\begin{array}{l}\text { save_grids } \\
\text { save_river_points } \\
\text { save_dam_points } \\
\text { save_basins_selected } \\
\text { save_basins_as_ascii } \\
\text { save_curves_as_excel }\end{array}$ & $\begin{array}{l}\text { input grids (yes } / \text { no: } 1 / 0, \text { Table } 4 \text { ) } \\
\text { general information on all analyzed river points (yes } / \text { no: } 1 / 0 \text {, Table } 4 \text { ) } \\
\text { information on all suitable basin locations (yes/no: } 1 / 0 \text {, Table } 4 \text { ) } \\
\text { detailed information on the selected basin combination (yes } / \text { no: } 1 / 0 \text {, Table } 4 \text { ) } \\
\text { ascii raster file for all sites with dam heights and water depths (yes } / \text { no: } 1 / 0 \text { ) } \\
\text { excel-file with basin characteristics and depth-storage-area-curves (yes } / \text { no: } 1 / 0 \text { ) }\end{array}$ \\
\hline plot_exitcodes & plot with spatial distribution of exit codes (yes/no: 1/0, Table 1) \\
\hline plot_spatial_overview & plot with spatial distribution of basins and dams (yes/no: 1/0) \\
\hline plot_factsheet_p1 & fact sheet, page 1: basin characteristics (yes/no: 1/0) \\
\hline plot_factsheet_p2 & fact sheet, page 2: characteristics of all dam heights of one site (yes/no: 1/0) \\
\hline plot_dam_comparison & plot second page of the fact sheet for multiple sites (yes/no: 1/0) \\
\hline plot_curve_comparison & plot water depth-storage-area-curves for multiple sites (yes/no: 1/0) \\
\hline plot_visibility & define whether the plot is visible during plotting (visible/only saving: 1/0) \\
\hline raster_selected.name & name of the background raster for the spatial plots (name from Table 2) \\
\hline raster_selected.legend & description of the raster ids in ascending order \\
\hline raster_selected.color & RGB-codes (0-1) of the raster ids in ascending order (one color per line) \\
\hline
\end{tabular}

\subsection{Output Data}

The most common output data configurations are summarized in Table 4. The variables to define the files to be saved are described in Table 3. The input grids and the user-defined exclusion information are saved in the file input_grids_used.mat, which may be required for the plotting of background maps. The file river_points . mat contains general information of all river points and enables an analysis of the reasons for the exclusion of specific river points (exit codes in Table 1). 
Table 4. Output data files and variables ("r": row, "c": column).

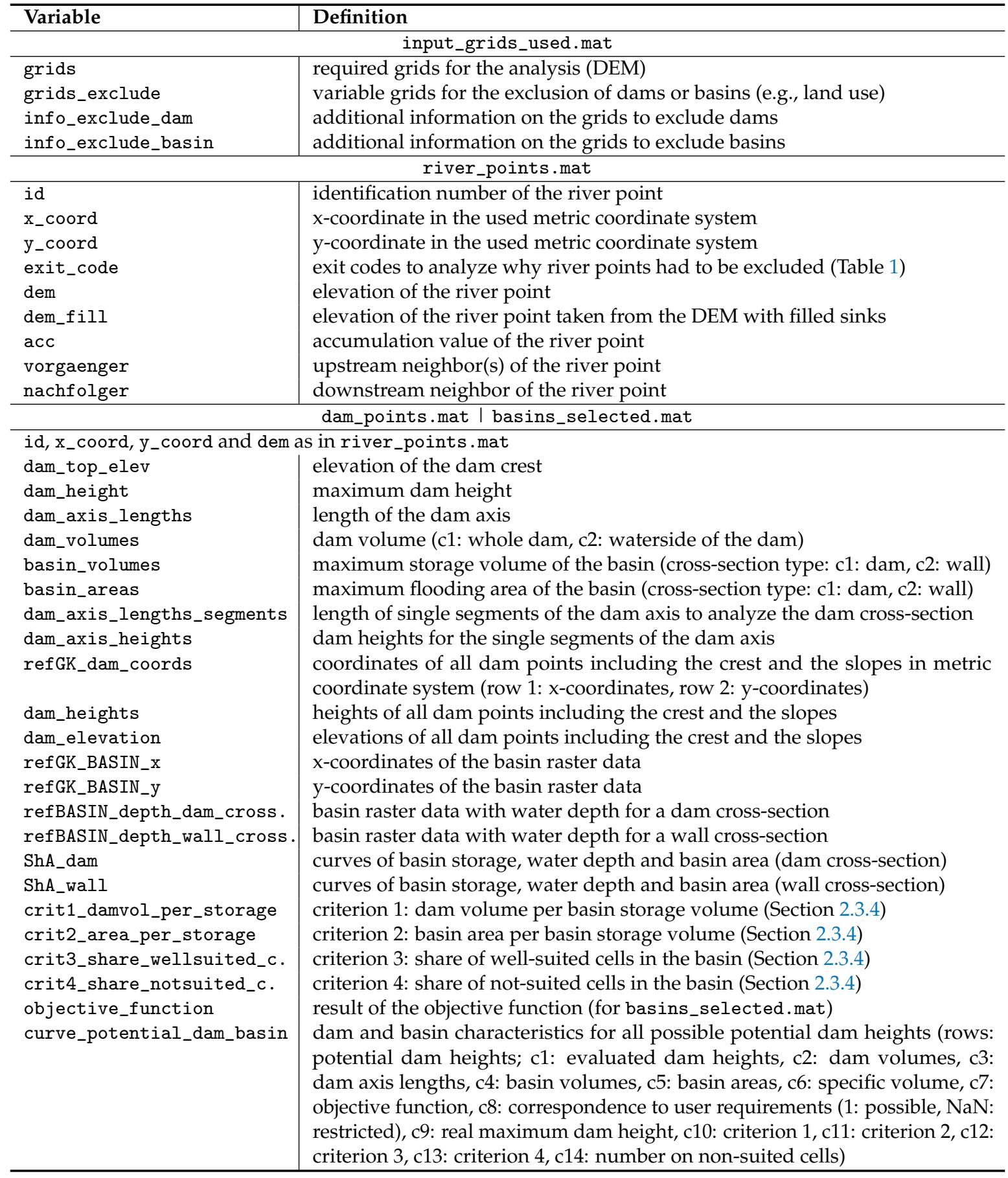

The detailed descriptions of possible dam sites are given in the files dam_points.mat and basins_selected.mat. The latter involves the dams of the selected combination and can be used for a combined efficiency analysis. In contrast, dam_points . mat contains all possible dam sites, which have not been excluded in the previous analysis. The file can be used to characterize potential dam sites and to conduct a manual selection of basin locations.

\section{Case Study}

The objective of the case study is to illustrate the applicability and flexibility of LOCASIN. We selected two area extents from the Main catchment in Bavaria (Germany) with maximum 
accumulation areas of about $5 \mathrm{~km}^{2}$ and $200 \mathrm{~km}^{2}$. The different catchment sizes and valley types of the sections allow one to detect a large range of basin volumes.

\subsection{Input Data and Parameters}

The required file names and parameters are summarized in Table 5. The four cases differ in terms of the spatial extent (region 1, region 2), raster resolution $(1 \mathrm{~m}, 5 \mathrm{~m})$ and specific dam and basin characteristics.

We defined two raster files to include or exclude potential dam sites. The raster river_buffer defines an area of $70 \mathrm{~m}$ along the real river network; potential dam points outside this range are excluded. The second raster contains land use information, which is used to exclude dam sites and to evaluate the suitability of the basins. Basins containing more than $1000 \mathrm{~m}^{2}$ of the land use classes 5 (large roads) or 6 (settlements) are excluded. The shares of well suited cells (1: grassland) and not suited cells are considered in the objective function for the dam and basin evaluation. The parameter to define the dam and basin characteristics differs in the ranges of dam heights and basin volumes. Furthermore, the level of detail varies with regard to the respective computational effort. The run and save options are identical. The threshold value is left empty and in is consequently defined based on the minimum basin volume and the maximum specific volume.

\subsection{Performance Evaluation}

The applicability of LOCASIN is flexible with regard to the input data and the raster resolution, the level of detail of the results and the computational effort. The results of the four cases and their visualization are described in Section 4.3. Table 6 gives an overview over the evaluation extents, i.e., the raster size and number of river points, and the resulting computational effort of the four cases (Intel(R) Xeon(R) CPU E3-1270 V2 at 3.50GHz, 32.0 GB RAM). While there is only a relatively small difference with regard to the raster resolution among case 1 and case 2 (factor: 4.2), the computation time of the basin analysis increases significantly by a factor of about 14.7 from case 3 to case 4 . In consequence, the required level of detail may be adjusted to obtain a reasonable computational effort.

\subsection{Results and Visualization}

The visualization of the results provides a basis for a plausibility check and an evaluation of the results. It includes six figures:

1. The spatial distribution of the river points is plotted with different colors for the exit codes (Table 1). Individual raster data (e.g., DEM) can be displayed as a background map. The purpose of the figure is to analyze the plausibility of the results and the sorting procedure (Figures A1a,c and A7a,c).

2. The selected basin combination is displayed to give an overview of the final results. It includes the basin number, the dam orientation with the respective dam heights and the basin area with distributed water depths. The background map includes the DEM, an individual map (e.g., landuse) and the river network (Figures A1b,d and A7b,d).

3. The characterization of the single basins is summarized on a double-sided fact sheet. The first page includes general information on the selected basin; curves of the water depths, the storage volume and the flooding area; the dam's cross-section; the basin longitudinal section; and a top view of the basin (Figures A3-A6, A9 and A10).

4. The second page displays information on all potential dam heights; i.e., the dam characteristics, the basin characteristics and the dam and basin evaluation criteria.

5. The curve of water depth, basin volume and basin area is decisive for the efficiency estimation and the influencing area of a basin. It is, thus, included on the first page of the fact sheet, but can additionally be compared among different dam sites. 
6. The second plot to compare multiple dam sites is based on the second page of the fact sheet. It may be relevant for decision making to manually evaluate potential dam sites and heights (Figures A2 and A8).

Table 5. Input data and parameter selection for the case study.

\begin{tabular}{|c|c|c|c|c|c|}
\hline \multirow{3}{*}{$\begin{array}{l}\text { Variable Name } \\
\text { investigation area } \\
\text { raster resolution }\end{array}$} & & Case 1 & Case 2 & Case 3 & Case 4 \\
\hline & & \multicolumn{2}{|c|}{ region 1} & \multicolumn{2}{|c|}{ region 2} \\
\hline & & $5 \mathrm{~m}$ & $1 \mathrm{~m}$ & $5 \mathrm{~m}$ & $1 \mathrm{~m}$ \\
\hline \multicolumn{6}{|c|}{ required and optional spatial input data } \\
\hline \multirow{6}{*}{\multicolumn{2}{|c|}{$\begin{array}{l}\text { grids_required.x_range } \\
\text { grids_required.y_range } \\
\text { grids_required.dem } \\
\text { grids_required.dem_fill } \\
\text { grids_required.dir } \\
\text { grids_required.acc }\end{array}$}} & \multicolumn{2}{|c|}{$[4,476,340,4,477,111]$} & \multicolumn{2}{|c|}{$[4,471,081,4,477,113]$} \\
\hline & & \multicolumn{2}{|c|}{$[5,548,272,5,549,619]$} & \multicolumn{2}{|c|}{$[5,543,462,5,546,414]$} \\
\hline & & dem5.txt & dem1.txt & $\operatorname{dem} 5 . t x t$ & dem1.txt \\
\hline & & demfill5.txt & demfill1.txt & demfill5.txt & demfill1.txt \\
\hline & & dir5.txt & dir1.txt & dir5.txt & dir1.txt \\
\hline & & $\operatorname{acc5.txt}$ & acc1.txt & $\operatorname{acc5} . t x t$ & $\operatorname{acc1.txt}$ \\
\hline info_exclude_dam.rives & & buffer5.txt & buffer1.txt & buffer5.txt & buffer1.txt \\
\hline info_exclude_dam.river & ude & & & & \\
\hline info_exclude_basin.lar & & use5.txt & use.txt & use5.txt & use.txt \\
\hline info_exclude_basin.lar & $\{1\}$ & & & & \\
\hline info_ $(\ldots)$. landuse.ex & $\operatorname{ld}\{1\}$ & & & & \\
\hline info_exclude_basin.lar & lited & & & & \\
\hline info_exclude_basin.lar & ted & & & & \\
\hline & to defi & dam and $b a$ & characteris & & \\
\hline dam_height_max & & & & & \\
\hline dam_height_min & & & & & \\
\hline dam_height_buffer & & & & & \\
\hline dam_length_max & & & & & \\
\hline exclude_longer_dams & & & & & \\
\hline basin_volume_max & & & & & 000 \\
\hline basin_volume_min & & & & & \\
\hline $\mathrm{sV} \_\max$ & & & & & \\
\hline sV_min & & & & & \\
\hline dam_slope_m & & & & & \\
\hline dam_crest_width & & & & & \\
\hline thresh & & & & & \\
\hline limit_dam_height & & & & & \\
\hline dam_dist_eval & & & & & \\
\hline discretization_number & & & & & \\
\hline neighbors_exclude_dist & & & & & \\
\hline w1_damVolume_per_basir & & & & & \\
\hline w2_basinArea_per_basir & & & & & \\
\hline w3_share_well_suited & & & & & \\
\hline w4_share_not_suited & & & & & \\
\hline & tting & ions (identi & for Case $1 \mathrm{t}$ & ase 4) & \\
\hline debug_on & 0 & plot_ & sibility & & 0 \\
\hline save_memory & 1 & & & & \\
\hline save_grids & 1 & plot_ & itcodes & & 1 \\
\hline save_river_points & 1 & plot_ & atial_over & & 1 \\
\hline save_dam_points & 0 & plot & ctsheet_p1 & & 1 \\
\hline save_basins_selected & 1 & plot_ & ctsheet_p2 & & 1 \\
\hline save_basins_as_ascii & 1 & plot_ & n_comparis $_{\text {- con }}$ & & 1 \\
\hline save_curves_as_excel & 1 & plot_ & cve_compar & & 1 \\
\hline
\end{tabular}


Table 6. Evaluation extent and computation time of the four cases.

\begin{tabular}{l|c|c|c|c}
\hline Parameter & Case 1 & Case 2 & Case 3 & Case 4 \\
\hline \multicolumn{4}{c}{ evaluation extent } \\
\hline raster size (cells) & $4.2 \times 10^{4}$ & $1.6 \times 10^{6}$ & $7.1 \times 10^{5}$ & $1.7 \times 10^{7}$ \\
potential sites & 653 & 4408 & 2660 & 15,546 \\
analyzed sites & 361 & 418 & 420 & 930 \\
possible sites & 147 & 148 & 56 & 68 \\
selected sites & 4 & 4 & 2 & 2.455 \\
\hline \multicolumn{4}{r}{ computation time (min) } \\
\hline preprocessing & 0.847 & 1.817 & 0.951 & 3.620 \\
dam analysis & 0.038 & 0.313 & 0.138 & 32.327 \\
basin analysis & 0.210 & 3.954 & 0.003 & 0.049 \\
combination selection & 0.001 & 0.007 & 0.578 & 24.860 \\
saving results & 0.011 & 0.087 & 1.374 & 66.012 \\
plotting results & 0.074 & 2.182 & 4.505 & \\
total duration & 2.022 & 8.547 &
\end{tabular}

Those six figures can be combined in multiple ways. In the following we show a possible arrangement of the figures for the four cases, which allows for a comparison of the effects of the raster resolution. Figures A1-A6 illustrate the results of case 1 and case 2, whereas Figures A7-A10 represent the results of case 3 and case 4 . The difference in grid resolution is more pronounced between cases 1 and 2 (Figures A3-A6) than between cases 3 and 4 (Figures A9 and A10), illustrating the dependence on the target size of the dam height and retention volume. On the one hand, the locations of the basins are not identical for different grid resolutions, which leads to different characteristics. On the other hand, the percentage influence of the grid resolution is distinctly larger for small basin and dam volumes. When searching for locations for larger basins, the grid resolution can be increased without substantial loss of information, which considerably reduces the compuational effort (Table 6).

\section{Conclusions}

Retention basins have multiple objectives, including flood and drought management. Due to different demands of the site characteristics, a flexible methodology is required to fulfill the respective needs. We presented an open-source MATLAB tool, LOCASIN, which allows one to automatically detect, evaluate and select basins based on user-defined characteristics. LOCASIN is highly customizable in terms of raster resolution, the desired dam and basin characteristics (e.g., dam length, dam height, basin volume, specific volume) and the input data types to evaluate the suitability of the basins (e.g., land use, hydraulic conductivities, groundwater levels). Given the flexibility of possible input data combinations, LOCASIN represents a tool that can be employed for multiple practical applications such as flood, drought and water resources management on small or large spatial scales.

Potential users of LOCASIN are policy makers who are responsible for an integrated and resilient water management system, water authorities and engineering offices designing water management systems and scientists evaluating mitigation strategies. The practical use of LOCASIN can be made easier by the addition of a graphical user interface and the resulting simplified usability. Within the scope of scientific studies, there is potential for improvement, especially in the scope of the objective function. In addition to the four factors used, environmental, social and economic assessment criteria could also be taken into account.

Author Contributions: Conceptualization, S.T. and D.B.; methodology, S.T.; software, S.T.; validation, S.T.; investigation, S.T.; writing—original draft preparation, S.T. and D.B; writing—review and editing, S.T., D.B. and M.D.; visualization, S.T.; supervision, M.D.; project administration, S.T.; funding acquisition, M.D. All authors have read and agreed to the published version of the manuscript.

Funding: This research was funded by Bayerisches Staatsministerium für Umwelt und Verbraucherschutz (Project ProNaHo). 
Acknowledgments: S.T. conducted this work in the framework of the ProNaHo project, funded by the Bayerisches Staatministerium für Umwelt und Verbraucherschutz. S.T. gratefully acknowledges the graduate centre of the Department Civil, Geo and Environmental Engineering of the Technical University of Munich (FGC-BGU). S.T. and D.B. acknowledge the DHG research fellowship for field studies. D.B. refers to the UNMIX project, supported by the Deutsche Forschungsgemeinschaft (DFG) through TUM International Graduate School for Science and Engineering (IGSSE, GSC 81), and the Interreg Central Europe project boDEREC-CE, funded by ERDF. All authors gratefully acknowledge the computer and data resources provided by the Leibniz Supercomputing Centre (www.lrz.de). Finally, all authors thank the Bayerisches Landesamt für Umwelt and the Bayerische Vermessungsverwaltung for the data provision.

Conflicts of Interest: The authors declare no conflict of interest. The funders had no role in the design of the study; in the collection, analyses, or interpretation of data; in the writing of the manuscript, or in the decision to publish the results.

\section{Software Availabiliy}

Software name:

Developer:

First official release:

Program language:

Program size:

Availability:

License:

Documentation:
LOCASIN

Sonja Teschemacher

2019

MATLAB

$1.7 \mathrm{MB}$

https://github.com/steschemacher/LOCASIN

BSD-3-Clause

README in Github repository with example dataset

In addition to the MATLAB code, a standalone executable of the program is provided, which allows users without a MATLAB license to apply LOCASIN. 


\section{Appendix A. Visualization of the Case Study}
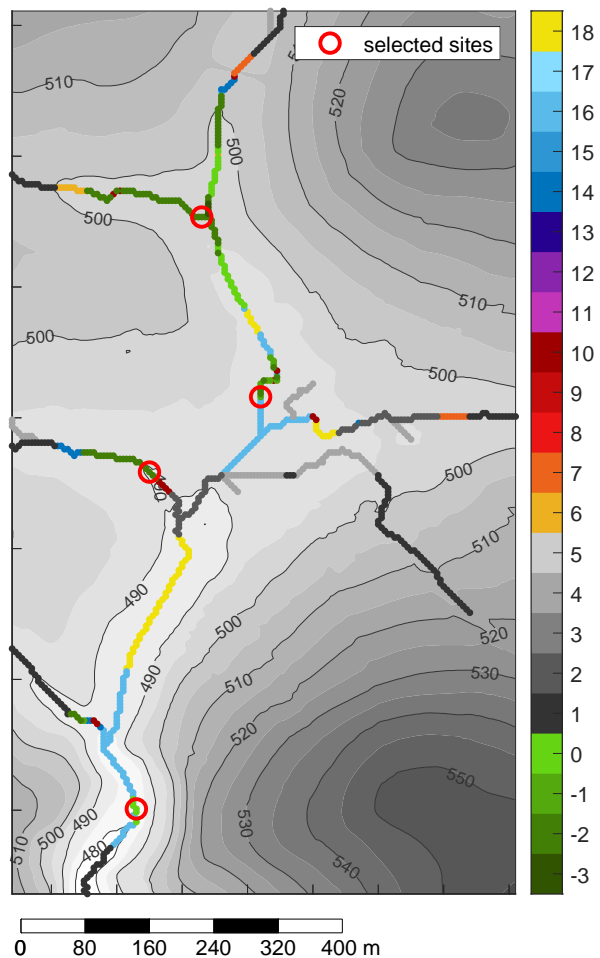

(a) exit codes (Table 1), raster: $5 \mathrm{~m}$

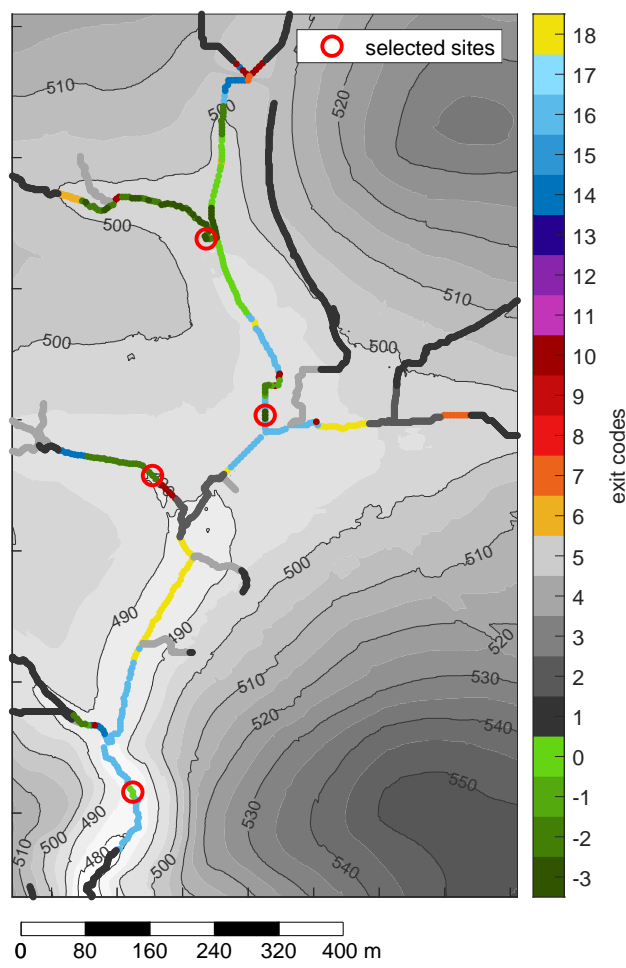

(c) exit codes (Table 1), raster: $1 \mathrm{~m}$.

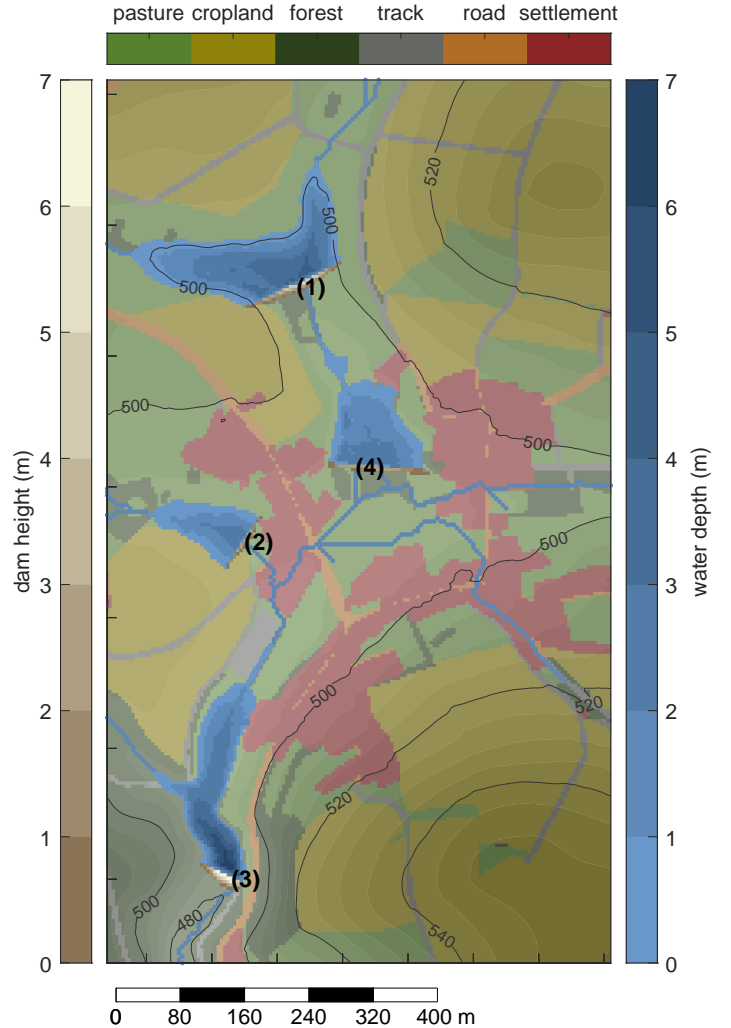

(b) basin distribution, raster: $5 \mathrm{~m}$

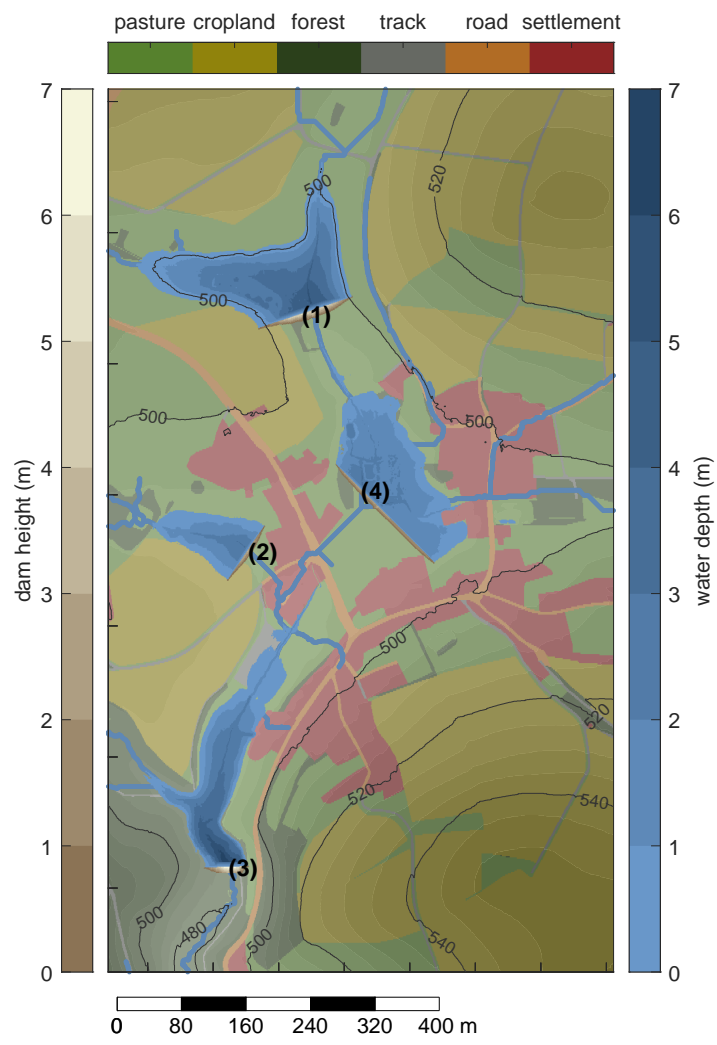

(d) basin distribution, raster: $1 \mathrm{~m}$.

Figure A1. Case 1 and case 2: overview of the results. 

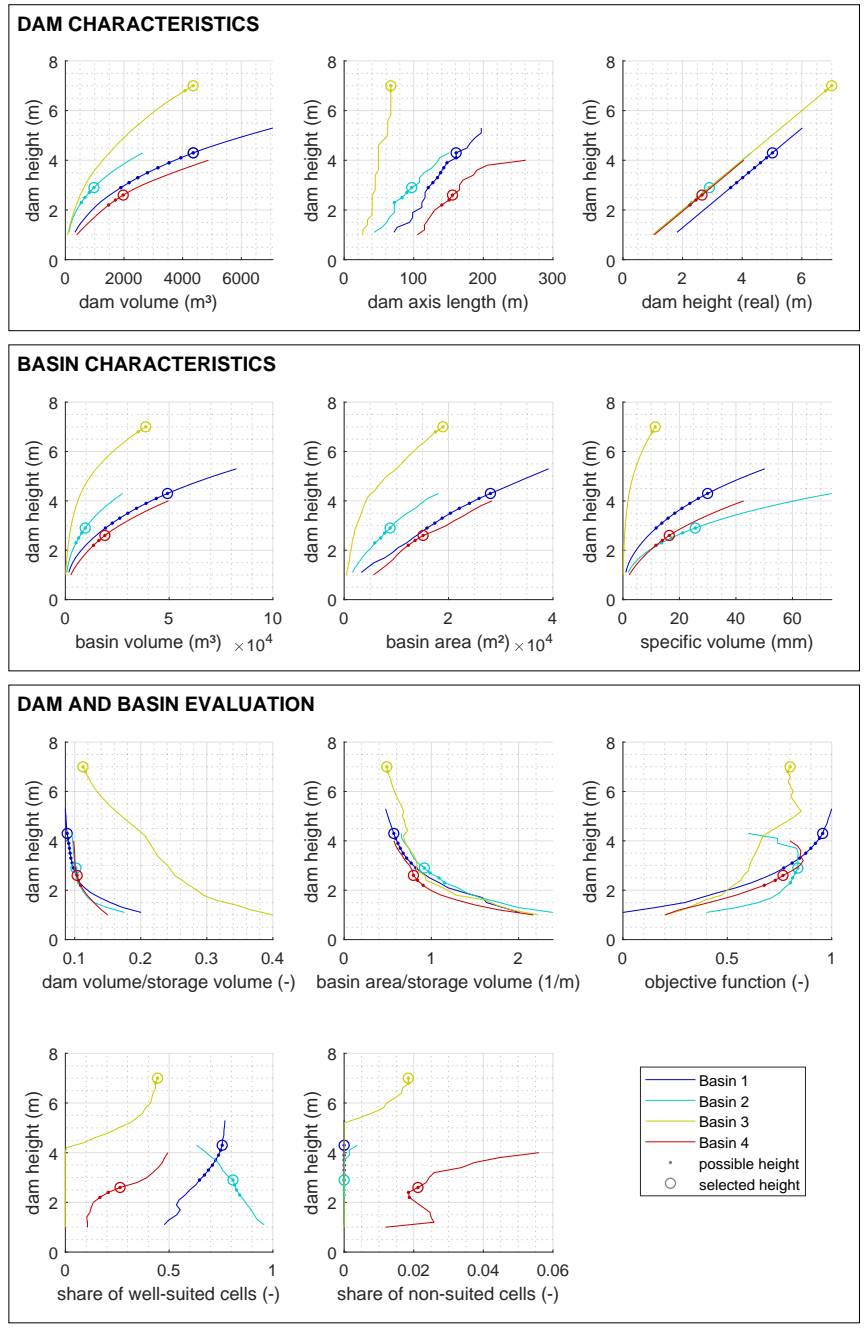

(a) raster: $5 \mathrm{~m}$

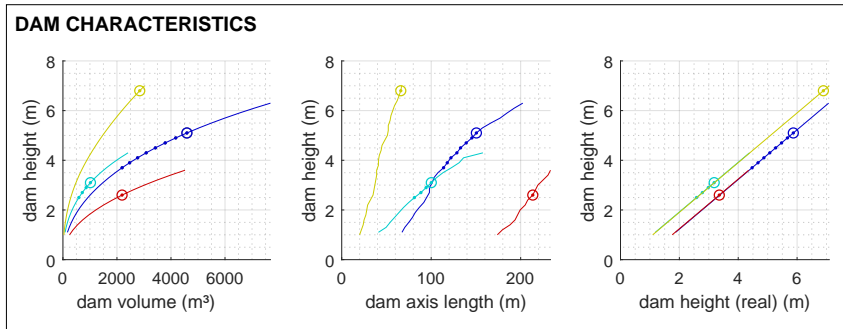

\section{BASIN CHARACTERISTICS}
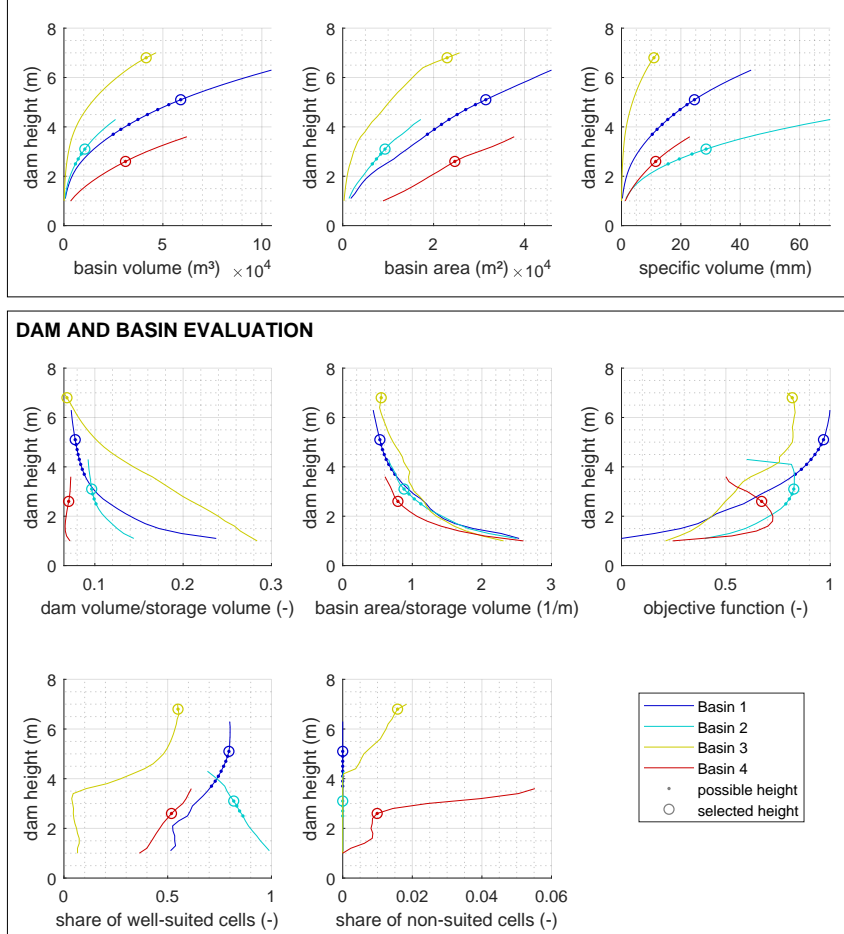

Figure A2. Case 1 and case 2: comparison of all potential dam heights.

b) raster: $1 \mathrm{~m}$ 


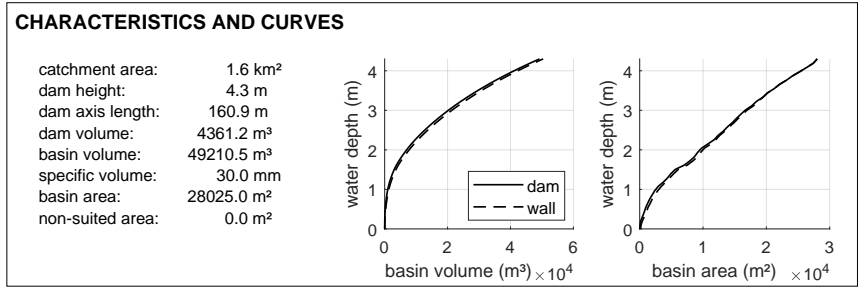

DAM CROSS SECTION AND BASIN LONGITUDINAL SECTION
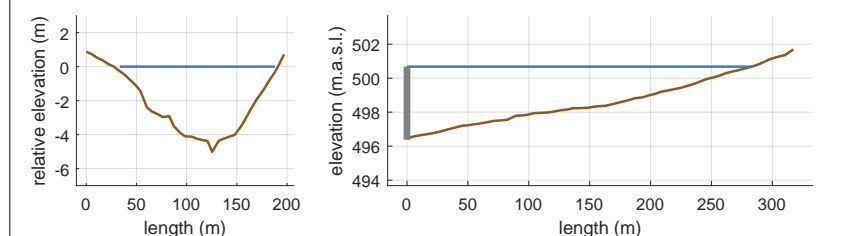

\section{SPATIAL DISTRIBUTION}

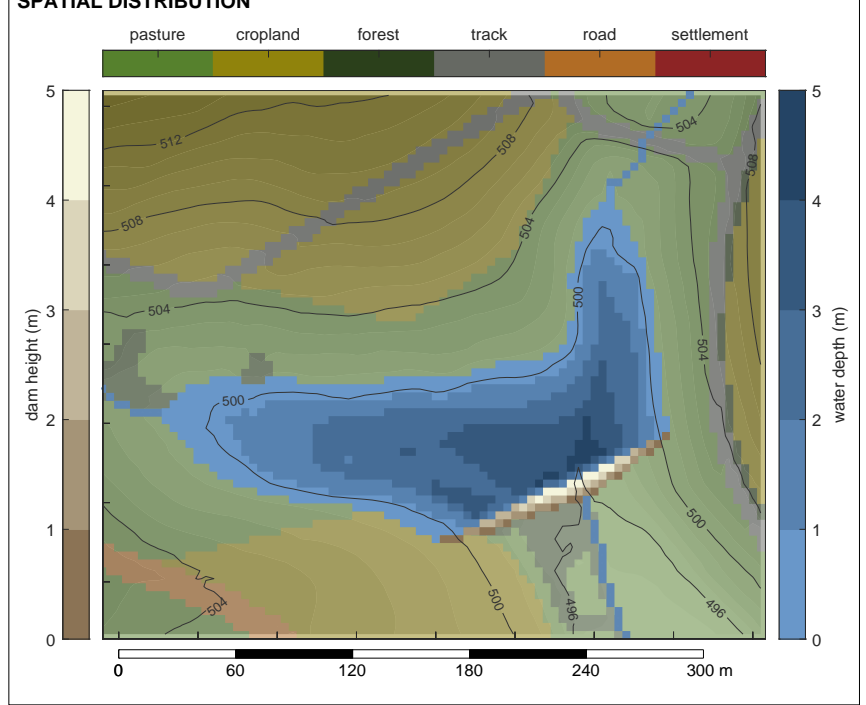

(a) raster: $5 \mathrm{~m}$

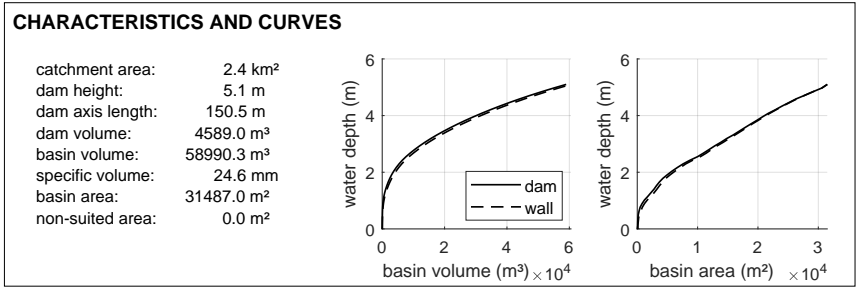

DAM CROSS SECTION AND BASIN LONGITUDINAL SECTION

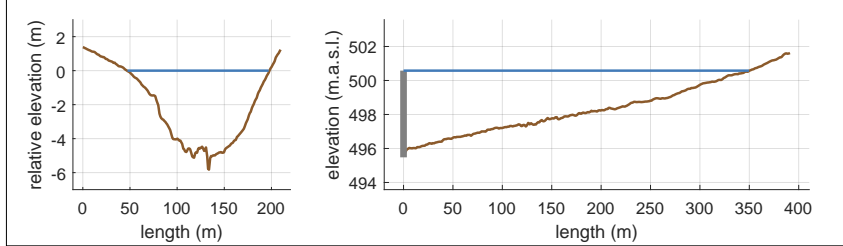

SPATIAL DISTRIBUTION

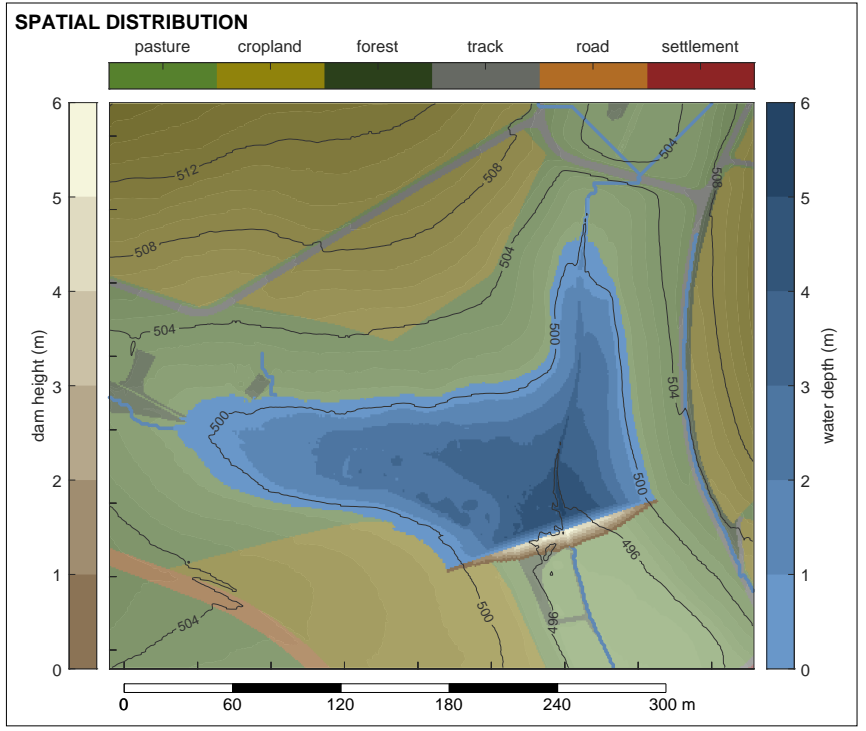

(b) raster: $1 \mathrm{~m}$

Figure A3. Fact sheet of basin 1: comparison of the raster resolution (case 1 and case 2). 


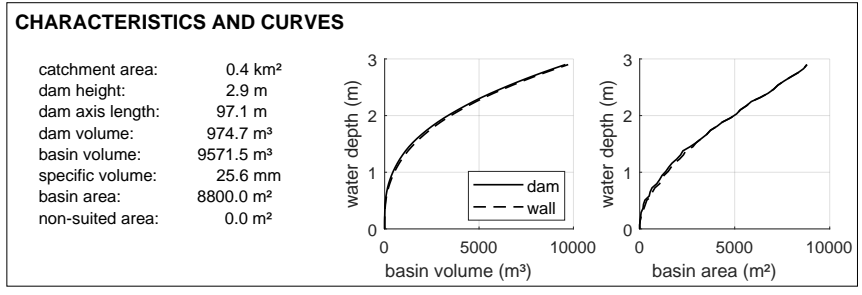

DAM CROSS SECTION AND BASIN LONGITUDINAL SECTION
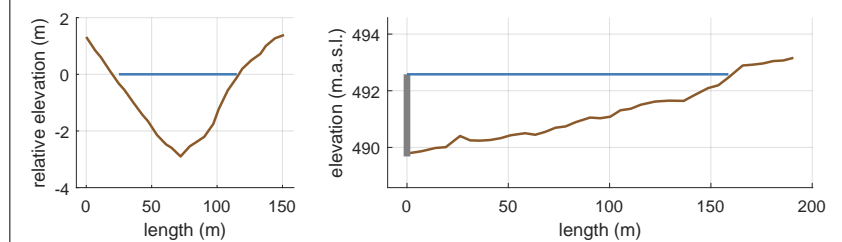

SPATIAL DISTRIBUTION

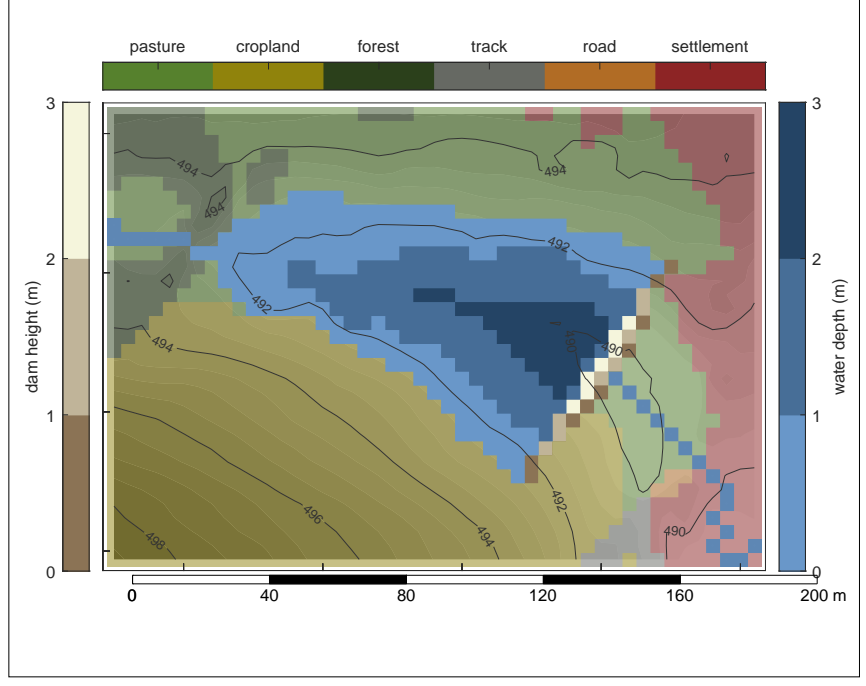

(a) raster: $5 \mathrm{~m}$

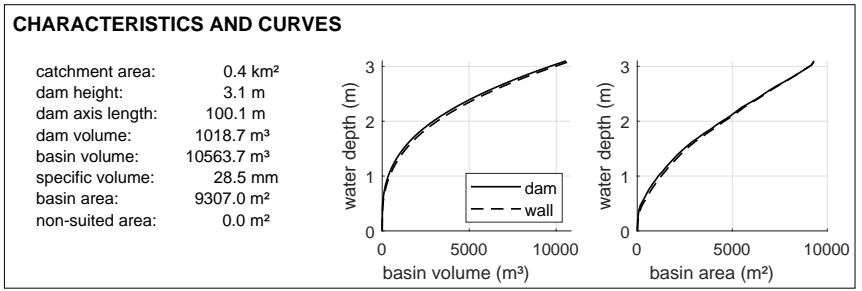

DAM CROSS SECTION AND BASIN LONGITUDINAL SECTION
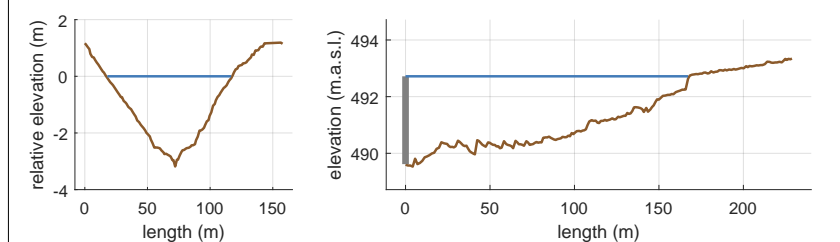

SPATIAL DISTRIBUTION

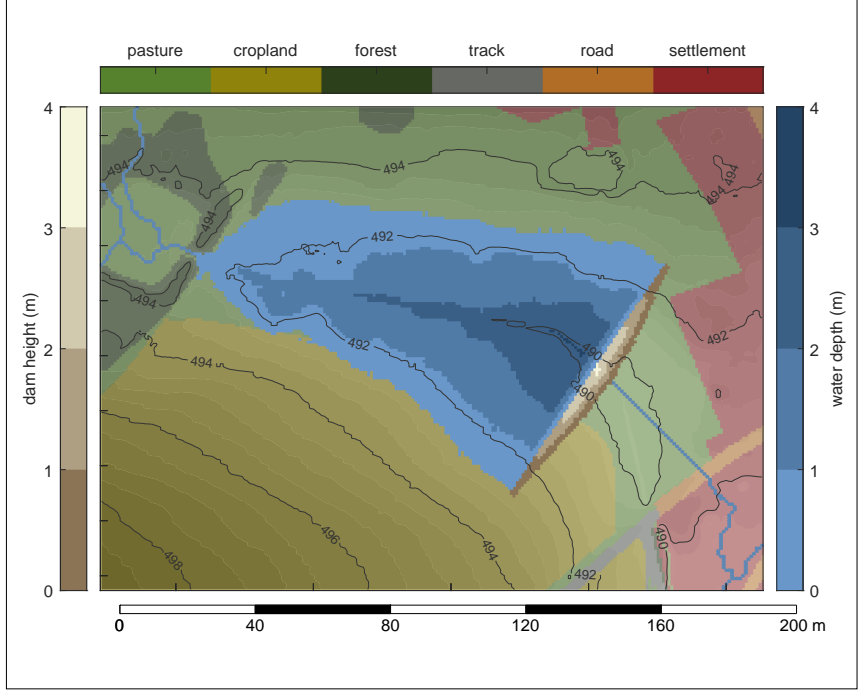

(b) raster: $1 \mathrm{~m}$

Figure A4. Fact sheet of basin 2: comparison of the raster resolution (case 1 and case 2). 


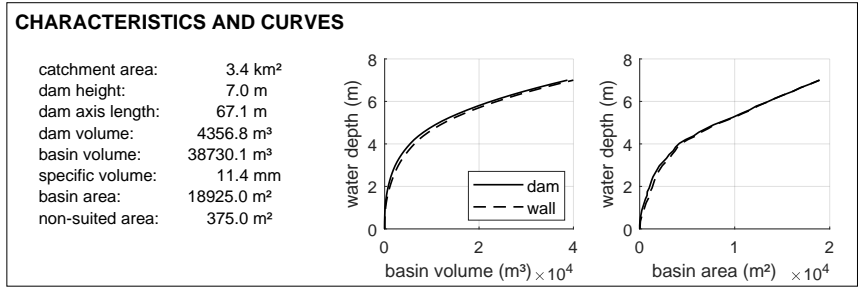

DAM CROSS SECTION AND BASIN LONGITUDINAL SECTION
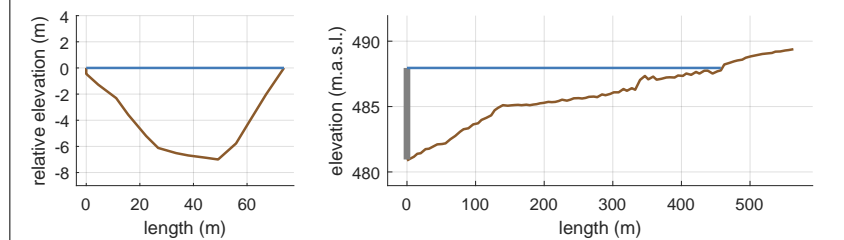

SPATIAL DISTRIBUTION

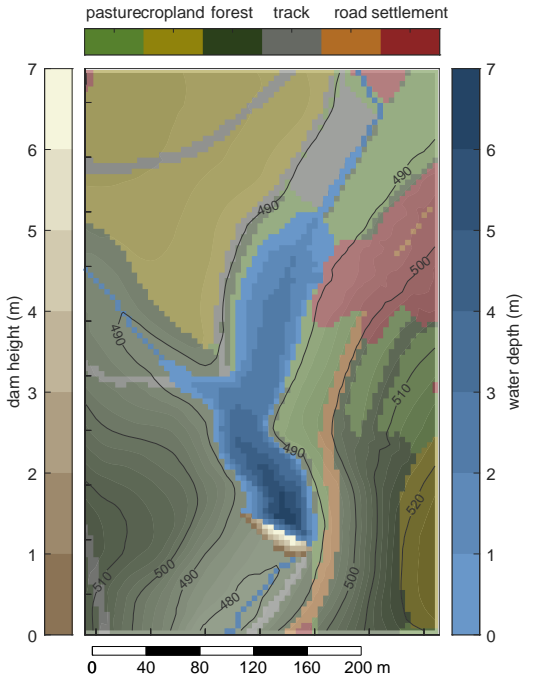

(a) raster: $5 \mathrm{~m}$
CHARACTERISTICS AND CURVES

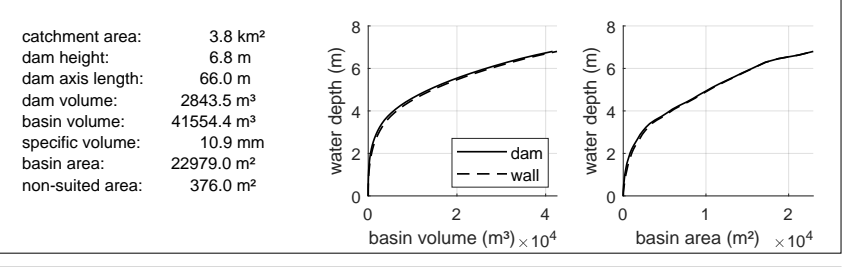

DAM CROSS SECTION AND BASIN LONGITUDINAL SECTION
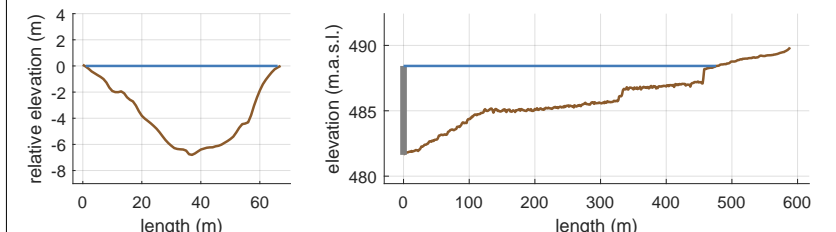

SPATIAL DISTRIBUTION

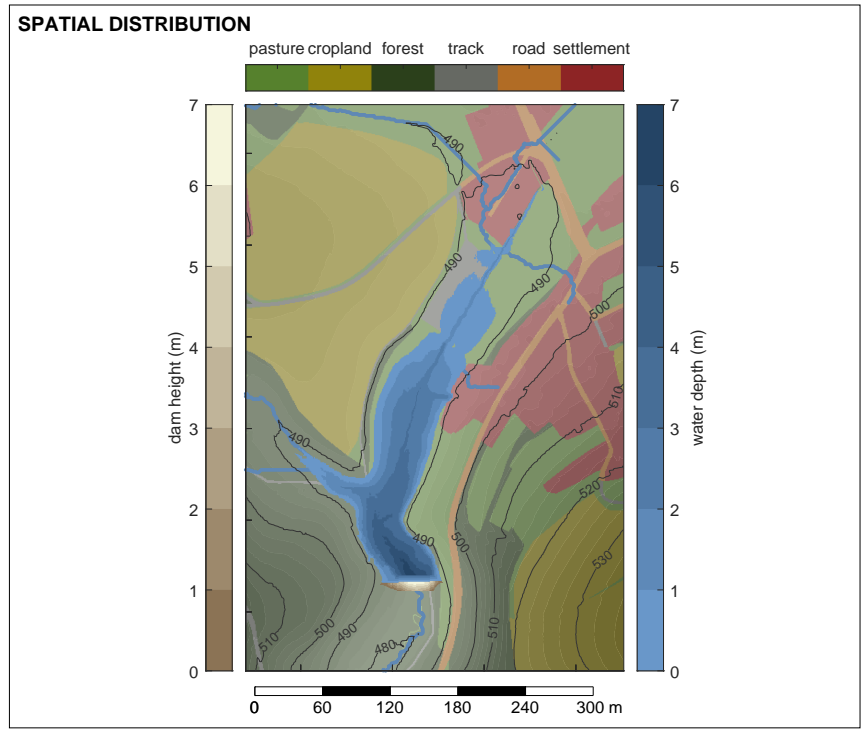

(b) raster: $1 \mathrm{~m}$

Figure A5. Fact sheet of basin 3: comparison of the raster resolution (case 1 and case 2). 


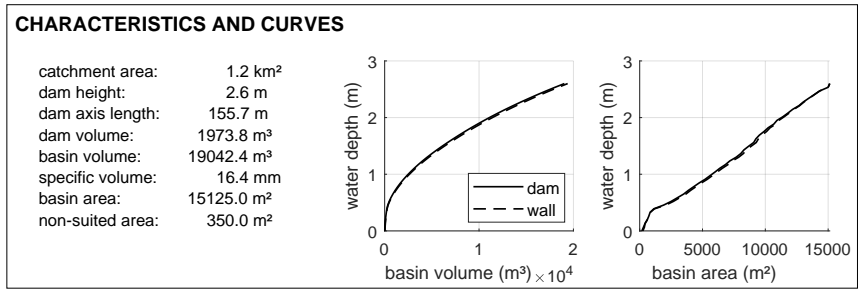

DAM CROSS SECTION AND BASIN LONGITUDINAL SECTION
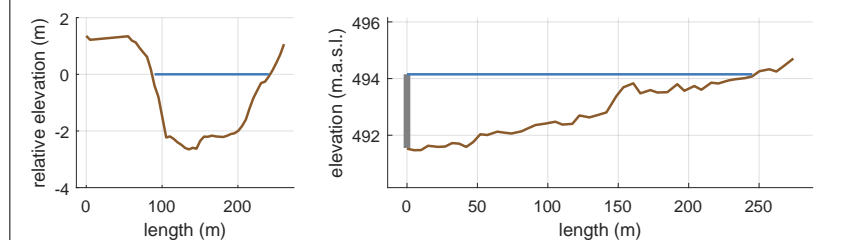

SPATIAL DISTRIBUTION

SPATIAL DISTRIBUTION
pasture cropland forest track road settlement

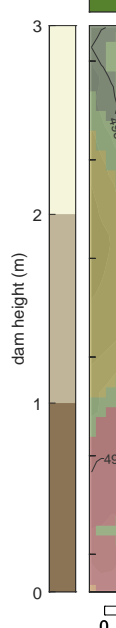

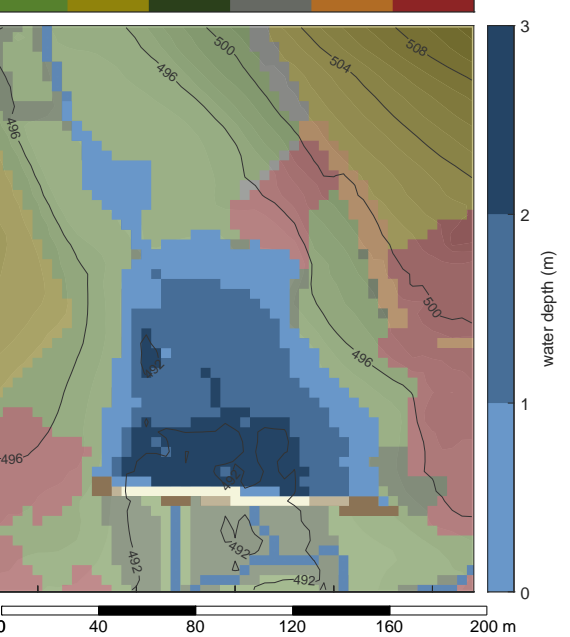

(a) raster: $5 \mathrm{~m}$
CHARACTERISTICS AND CURVES

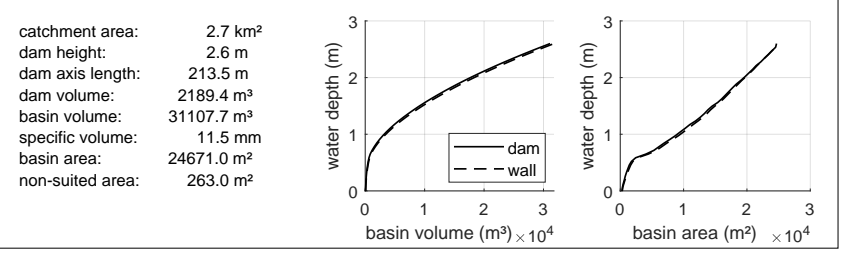

DAM CROSS SECTION AND BASIN LONGITUDINAL SECTION
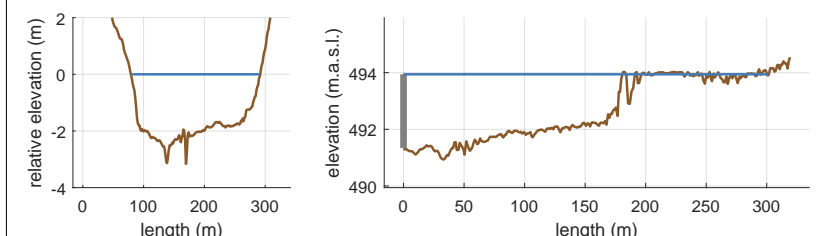

SPATIAL DISTRIBUTION

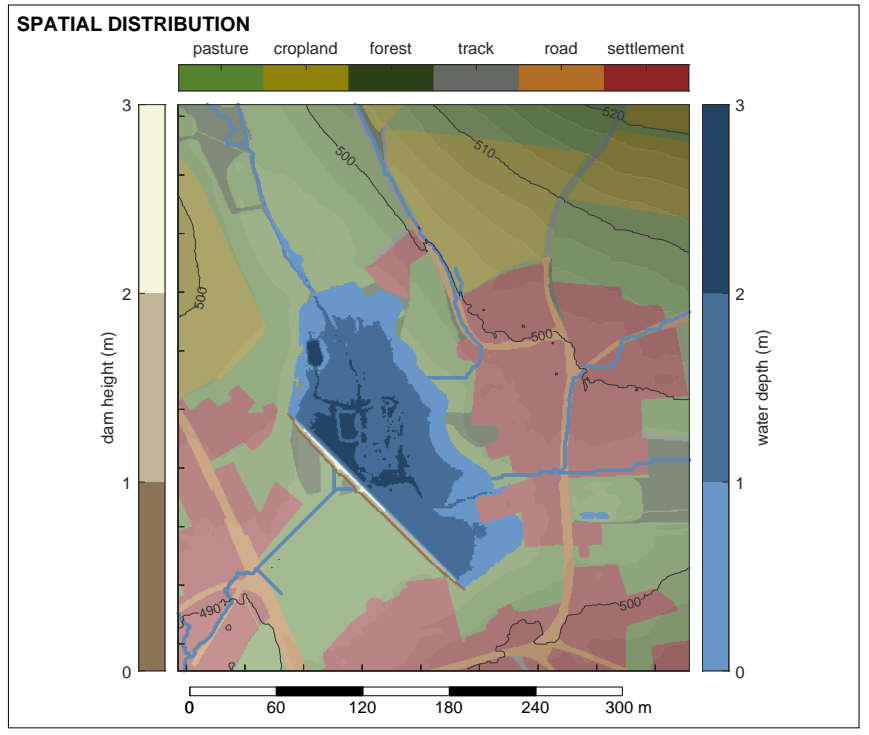

(b) raster: $1 \mathrm{~m}$

Figure A6. Fact sheet of basin 4: comparison of the raster resolution (case 1 and case 2). 


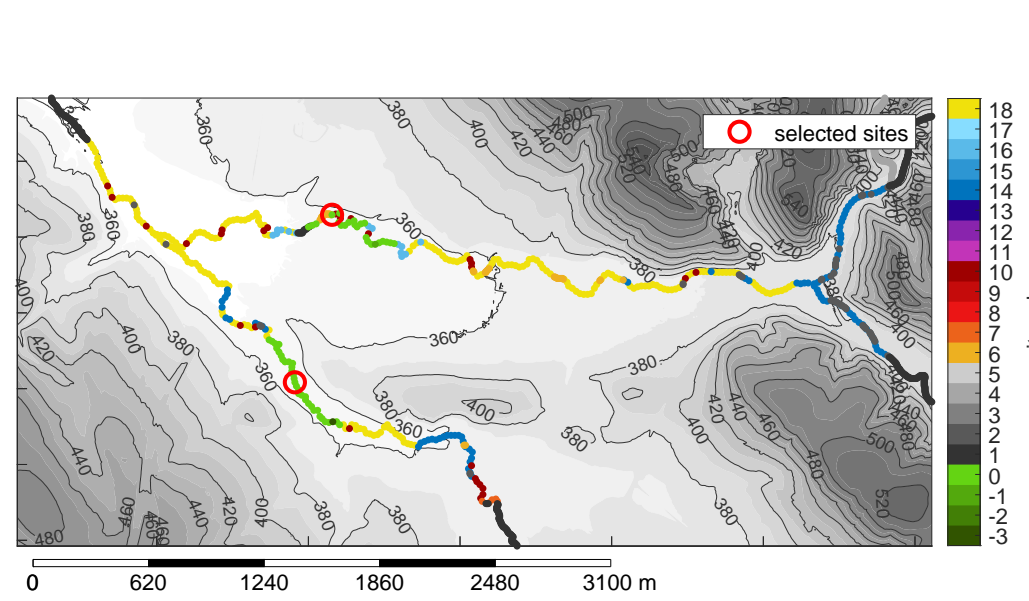

(a) exit codes (Table 1), raster: $5 \mathrm{~m}$

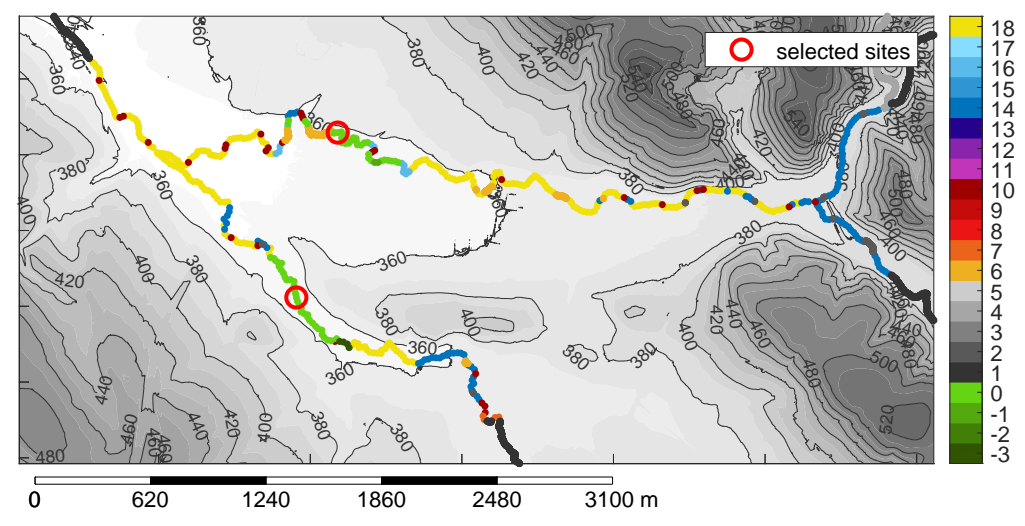

(c) exit codes (Table 1), raster: $1 \mathrm{~m}$

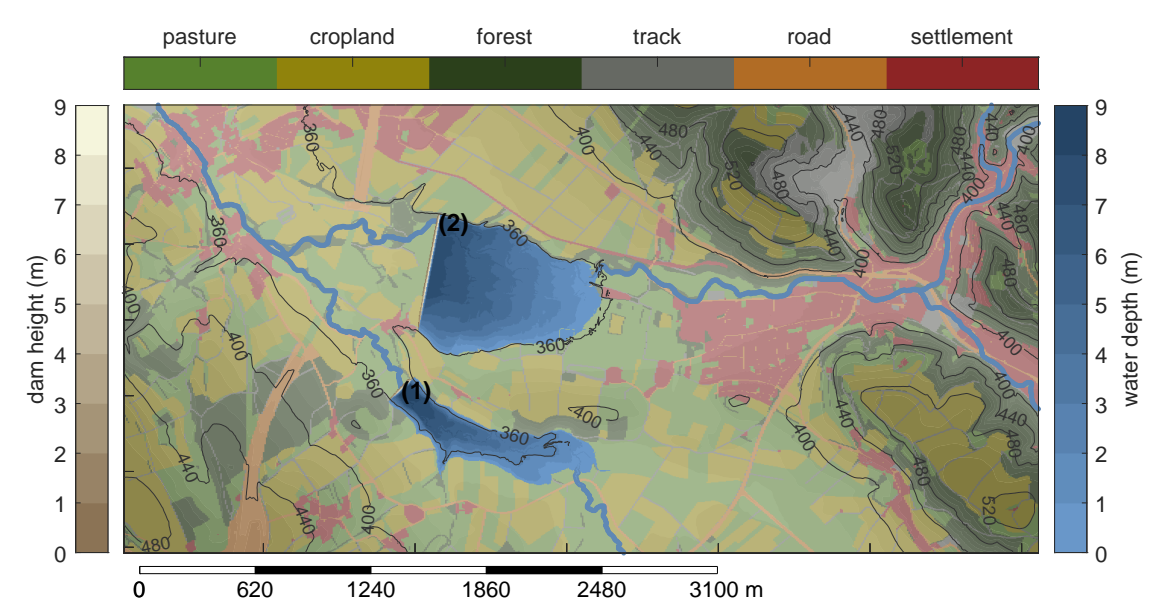

(b) basin distribution, raster: $5 \mathrm{~m}$

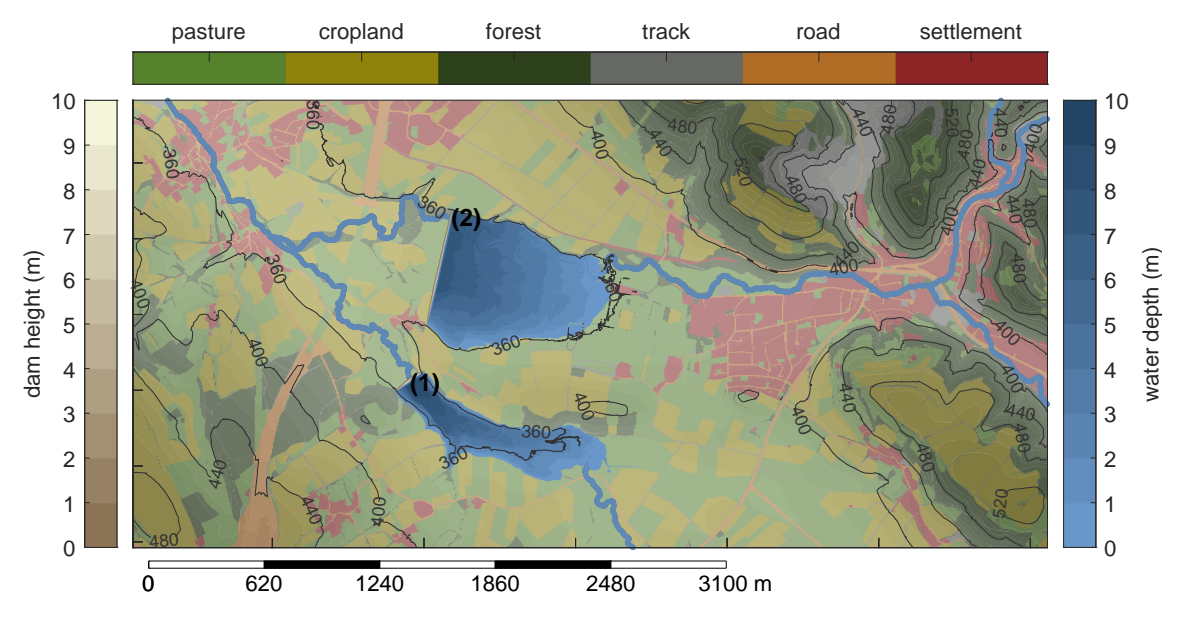

(d) basin distribution,raster: $1 \mathrm{~m}$

Figure A7. Case 3 and case 4: overview of the results. 

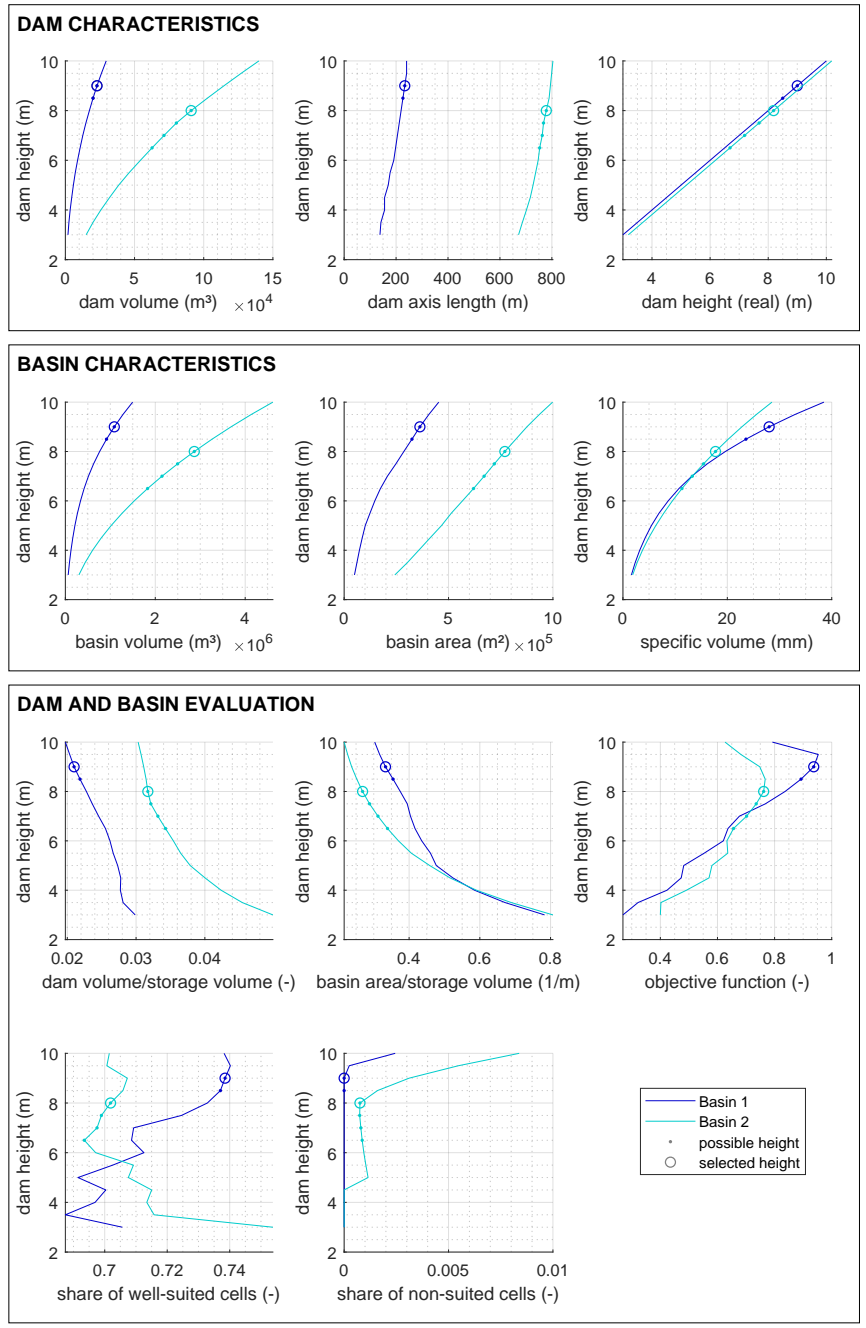

(a) raster: $5 \mathrm{~m}$

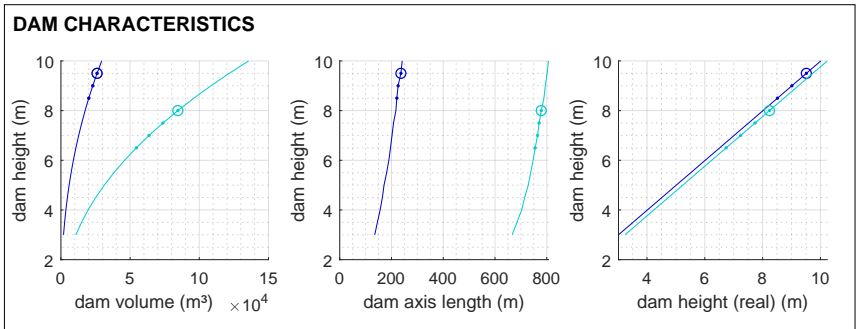

\section{BASIN CHARACTERISTICS}
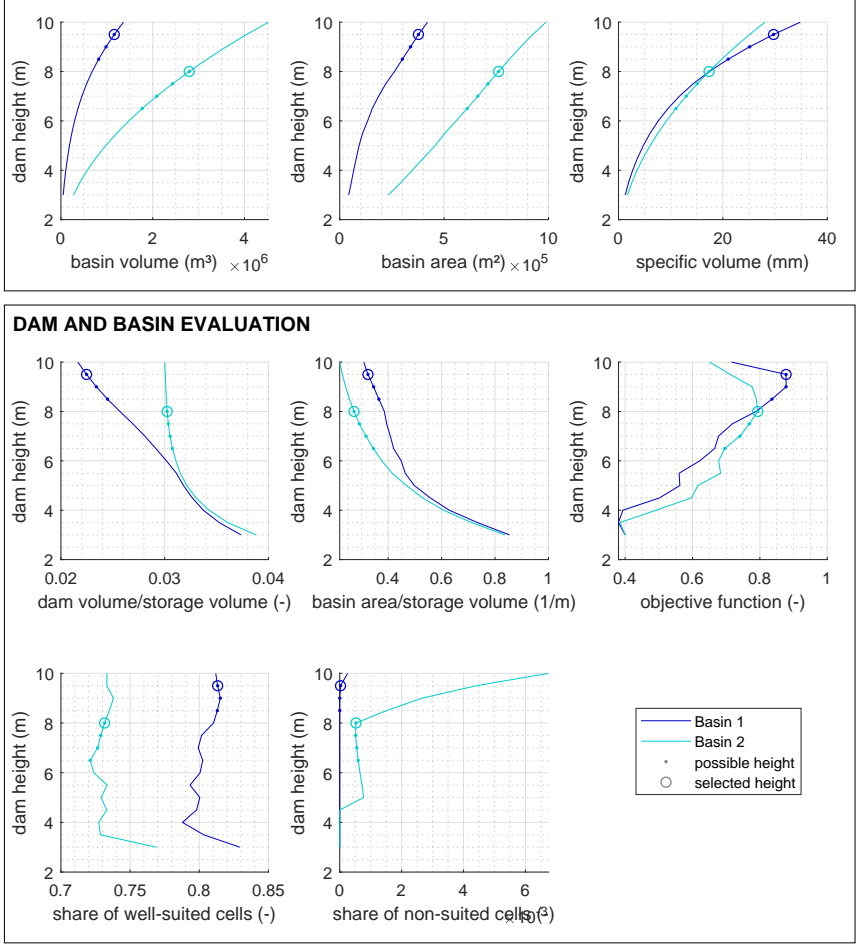

(b) raster: $5 \mathrm{~m}$

Figure A8. Case 3 and case 4: comparison of all potential dam heights. 


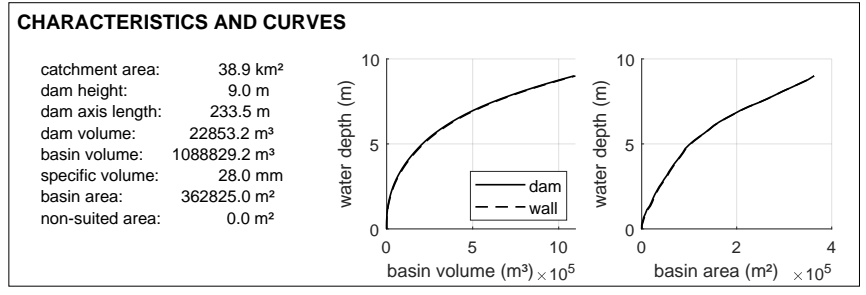

DAM CROSS SECTION AND BASIN LONGITUDINAL SECTION
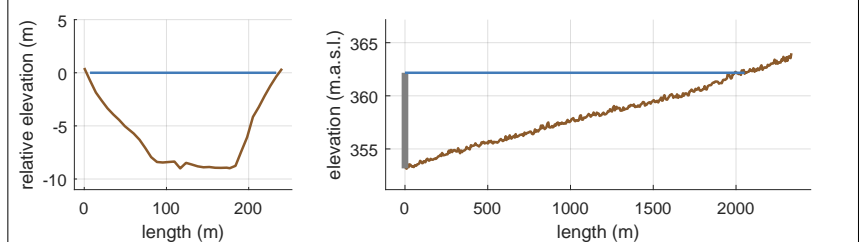

SPATIAL DISTRIBUTION

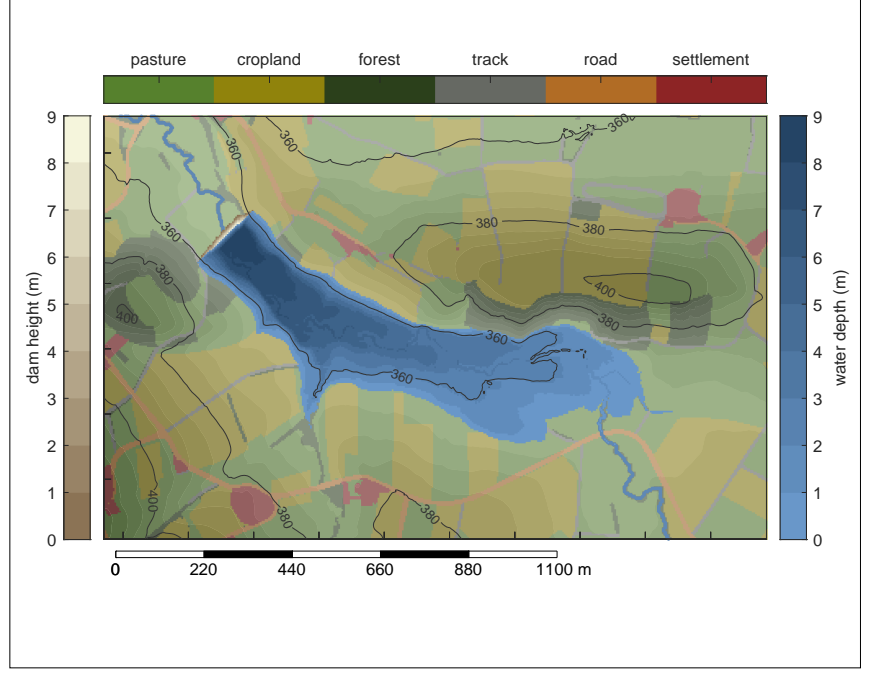

(a) raster: $5 \mathrm{~m}$

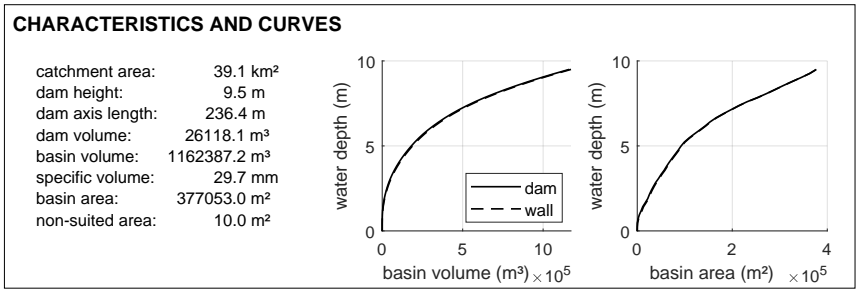

DAM CROSS SECTION AND BASIN LONGITUDINAL SECTION
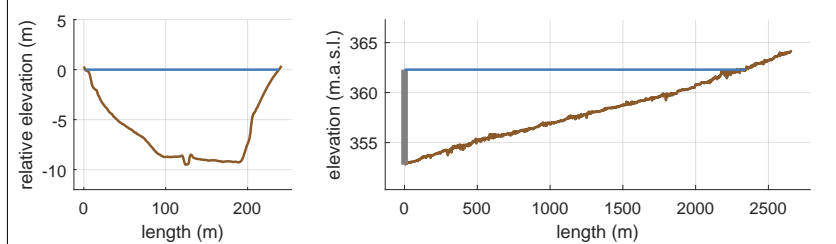

SPATIAL DISTRIBUTION

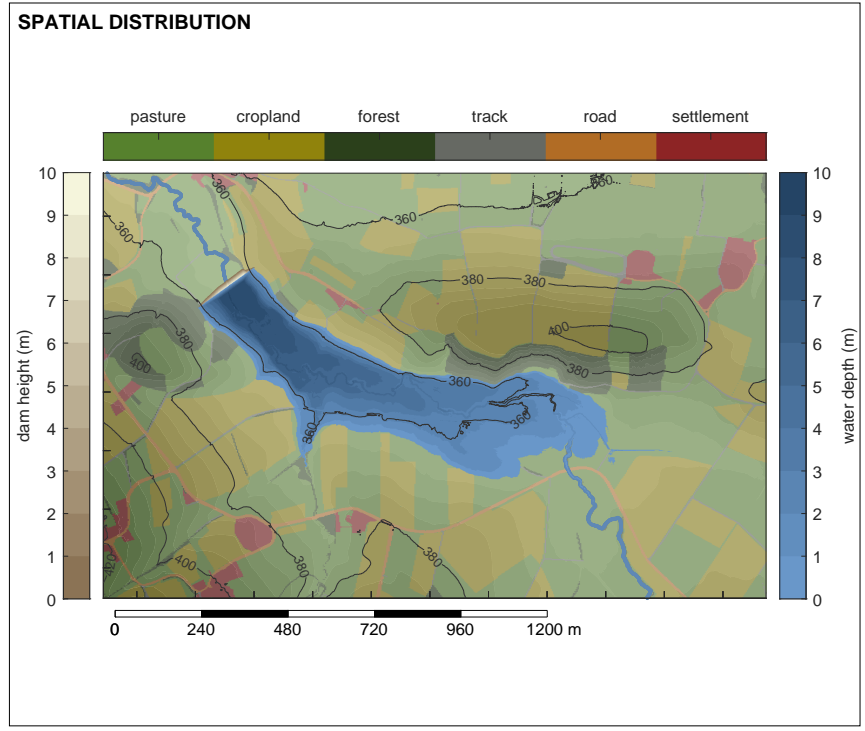

(b) raster: $1 \mathrm{~m}$

Figure A9. Fact sheet of basin 1: comparison of the raster resolution (case 3 and case 4). 


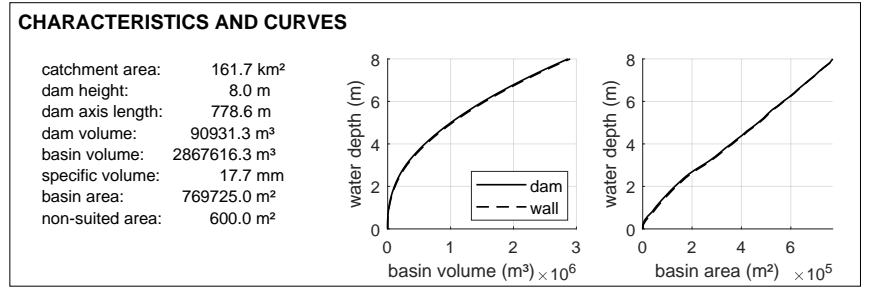

DAM CROSS SECTION AND BASIN LONGITUDINAL SECTION
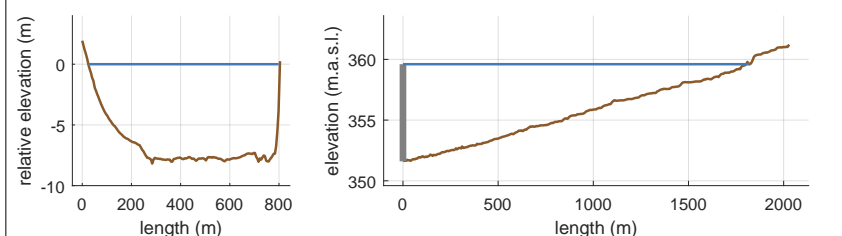

\section{SPATIAL DISTRIBUTION}

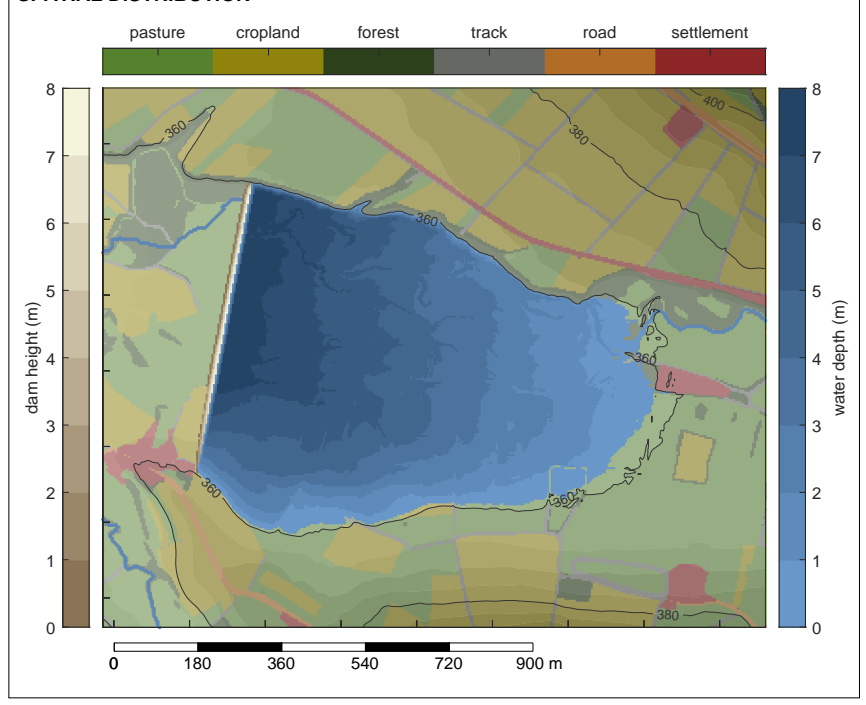

(a) raster: $5 \mathrm{~m}$
CHARACTERISTICS AND CURVES

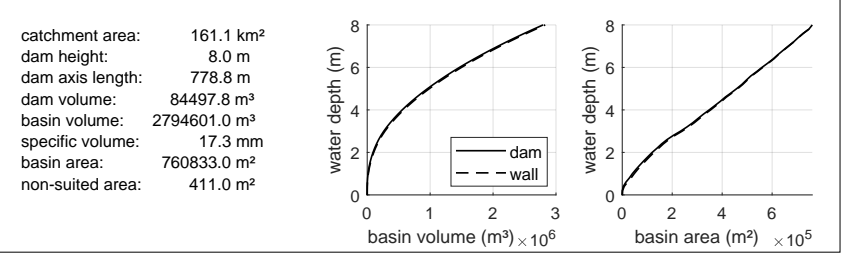

DAM CROSS SECTION AND BASIN LONGITUDINAL SECTION
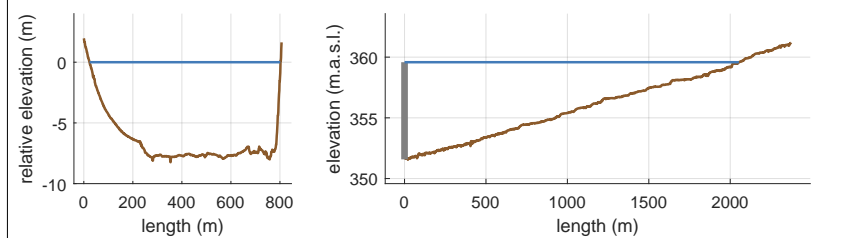

SPATIAL DISTRIBUTION

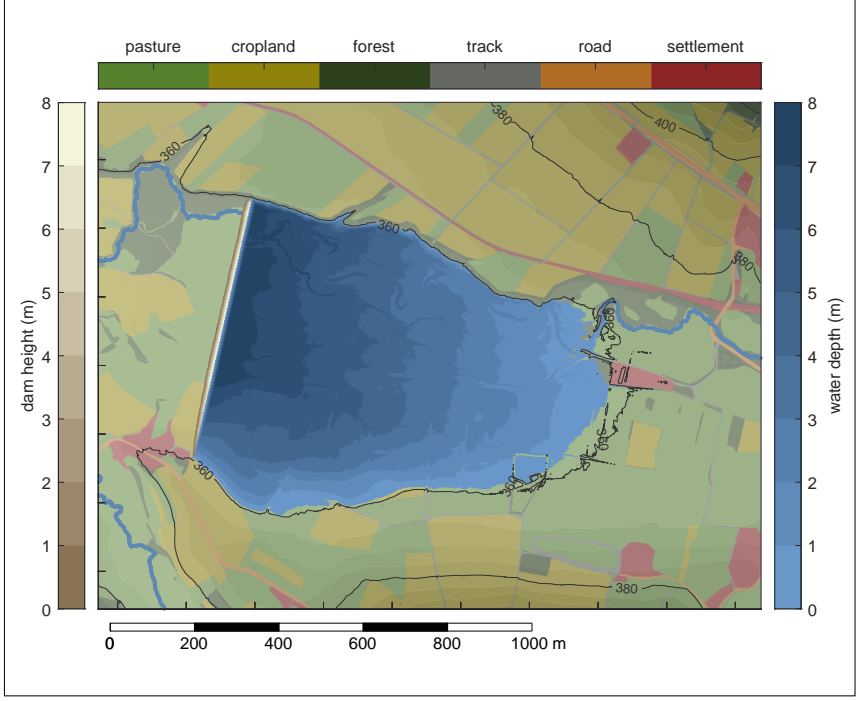

(b) raster: $1 \mathrm{~m}$

Figure A10. Fact sheet of basin 2: comparison of the raster resolution (case 3 and case4) 


\section{Appendix B. Tutorial}

The tutorial is structured in three sections and provides step-by-step instructions to apply LOCASIN on a small test case. It is located in the Main catchment (Bavaria, Germany) and has a size of about $1 \mathrm{~km}^{2}$. The standard use of LOCASIN requires a MATLAB license and allows an adaption of the code itself. Alternatively, the site-specific input data can be defined in an Excel-table to run the program with a compiled executable.

\section{Appendix B.1. Input Data}

The input data for the test case is already prepared from several raw data sources. The overview of the used input data ais given in Appendix B.1.1. The exemplary steps for the data preprocessing are described in Appendix B.1.2.

\section{Appendix B.1.1. Data Overview}

The test data set comprises six ascii raster files, which are located in the folder testcase. Three of them are required for the analysis (dem, dir, acc), whereas the others are included in the evaluation of the dam sites or are used for visualization purposes. All raster files need to have the same spatial extent and the same raster resolution.

$\begin{array}{ll}\text { dem.txt } & \text { digital elevation model (DEM) in a resolution of } 5 \mathrm{~m} \text { (required) } \\ \text { dem_fill.txt } & \text { DEM with filled sinks (optional) } \\ \text { dir.txt } & \text { flow directions (required) } \\ \text { acc.txt } & \text { flow accumulations (required) } \\ \text { buffer.txt } & \text { definition of a 70 m buffer around the river network (optional) } \\ \text { landuse.txt } & \text { map with land use classification numbers (optional) }\end{array}$

\section{Appendix B.1.2. Data Generation}

The generation of the input data can be based on a variety of data sources and can be performed in multiple ways. The following procedure is an example for the dataset in Appendix B.1.1, which was done in the scope of the project ProNaHo [24]. We used ArcMap 10.4.1 [25] for the preprocessing.

dem.txt The DEM [26] was aggregated from a resolution of $1 \mathrm{~m}$ to $5 \mathrm{~m}$. To use all features of LOCASIN, the DEM needs to cover all upstream borders of the catchment.

[Spatial Analyst Tools $\rightarrow$ Generalization $\rightarrow$ Aggregate (aggregation technique: mean)]

dem_fill.txt The following flow direction and accumulation analysis requires a DEM with filled sinks.

[Spatial Analysist Tools $\rightarrow$ Hydrology $\rightarrow$ Fill]

dir.txt The flow directions were determined on the basis of the DEM with filled sinks.

[Spatial Analyst Tools $\rightarrow$ Hydrology $\rightarrow$ Flow Direction]

acc.txt The flow accumulation raster was determined on the basis of the flow direction raster. If the raster covers the upstream borders of the catchment, the resulting cell values give information on the respective catchment area.

[Spatial Analyst Tools $\rightarrow$ Hydrology $\rightarrow$ Flow Accumulation]

buffer.txt The derived river network from the flow accumulation raster may not correspond to the real river network [27]. Thus, a buffer of $70 \mathrm{~m}$ around the real river network shapefile was determined in order to include only river cells within this range for the analyses.

[Analysis Tools $\rightarrow$ Proximity $\rightarrow$ Buffer; Conversion Tools $\rightarrow$ To Raster $\rightarrow$ Polygon to Raster]

landuse.txt The land use shapefile [28] was classified based on the potential suitability for basin locations and converted to a raster.

[Conversion Tools $\rightarrow$ To Raster $\rightarrow$ Polygon to Raster] 


\section{Appendix B.2. Parameter Setting}

The parameter values can be defined in the USER_INPUT . $m$ file, which is called in the beginning of the program. Alternatively, the parameter setting can be done in an Excel-file with a specific structure (e.g., user_input.xls $x$ in the directory testcase). The function USER_INPUT_from_xlsx.m imports the Excel-file and allocates the respective variables, where the location and the name of the Excel-file is defined in define_input_directory_and_file.txt. The selection of the USER_INPUT source is defined in the beginning of LOCASIN.m. The compiled executable LOCASIN can only be run based on the parameter setting from the Excel-file.

\section{Appendix B.2.1. Spatial Input Data}

The required and optional spatial input data have to be defined according to the generated data being described in Appendix B.1 and are summarized in Table A1. The names of the structure grids_required are fixed, whereas the fields of info_exclude_dam and info_exclude_basin are adjustable. The definition of basins to be excluded based on the maximum area of a specific raster value is flexible and can be adapted manually. In this example, basins are excluded, which comprise more than $100 \mathrm{~m}^{2}$ of settlements or large roads or more than $1000 \mathrm{~m}^{2}$ of small roads.

Table A1. Definition of spatial input data: variable names and selected values.

\begin{tabular}{lc}
\hline Variable Name & Selected Value \\
\hline grids_required.dem & dem5.txt \\
grids_required.dem_fill & dem_fill5.txt \\
grids_required.dir & dir5.txt \\
grids_required.acc & acc5.txt \\
\hline info_exclude_dam.river_buffer.name & buffer5.txt \\
info_exclude_dam.river_buffer.include & 70 \\
info_exclude_basin.landuse.name & landuse5.txt \\
info_exclude_basin.landuse.exclude\{1\} & {$[5,6]$} \\
info_exclude_basin.landuse.exclude_threshold\{1\} & 100 \\
info_exclude_basin.landuse.exclude\{2\} & {$[4]$} \\
info_exclude_basin.landuse.exclude_threshold\{2\} & 1000 \\
info_exclude_basin.landuse.well_suited & 1 \\
info_exclude_basin.landuse.not_suited & {$[5,6]$} \\
\hline
\end{tabular}

Appendix B.2.2. Basin Characteristics, and Save and Plot Options

The parameters which describe the dam and basin characteristics are defined for the purpose of identifying small retention basins (Table A2). The threshold to define rivers (thresh) can be left empty, because the maximum specific Volume (sV_max) was defined. Additional variables define the required output to be saved, and the plots, which are included in the visual representations of the results.

\section{Appendix B.3. Run LOCASIN}

LOCASIN can be run directly in MATLAB by executing the script LOCASIN. $\mathrm{m}$ or by selecting the executable LOCASIN.exe. Prior to the calculation of the testcase, the directories need to be adapted:

- Code: adaption of the data and result directories in USER_INPUT .m.

- Executable: adaption of the directory in define_input_directory_and_file.txt to the location of the Excel-file user_input.xlsx and adaption of the data and result directories in the first sheet of the Excel-file. 
Table A2. Definitions of basin characteristics, and save and plot options.

\begin{tabular}{lc}
\hline Variable Name & Selected Value \\
\hline dam_height_max & 6 \\
dam_height_min & 1 \\
dam_height_buffer & 0.05 \\
dam_length_max & 70 \\
exclude_longer_dams & 0 \\
basin_volume_max & 500,000 \\
basin_volume_min & 5000 \\
sV_max & 40 \\
sV_min & 10 \\
\hline dam_slope_m & 2 \\
dam_crest_width & 3 \\
\hline thresh & {$[1$} \\
limit_dam_height & 1 \\
dam_dist_eval & 0.2 \\
discretization_number & 41 \\
neighbors_exclude_distance & 0 \\
\hline w1_damVolume_per_basinVolume & 0.3 \\
w2_basinArea_per_basinVolume & 0.3 \\
w3_share_well_suited & 0.2 \\
w4_share_not_suited & 0.2 \\
\hline debug_on & 0 \\
save_memory & 1 \\
\hline save_grids & 1 \\
save_river_points & 1 \\
save_dam_points & 1 \\
save_basins_selected & 1 \\
save_basins_as_ascii & 1 \\
save_curves_as_excel & 1 \\
plot_exitcodes & 1 \\
plot_spatial_overview & 1 \\
plot_factsheet_p1 & 1 \\
plot_factsheet_p2 & 1 \\
plot_dam_comparison & 1 \\
plot_curve_comparison & 1 \\
plot_visibility & 1 \\
\hline
\end{tabular}

\section{Appendix B.4. Results and Visualization}

The visualization of the results includes three groups: the characteristics of the basins, the characteristics of the dam sites and the overview of the selection procedure.

Basin Characteristics The defined parameter values result in two very diverse basin positions for the analyzed river section (Figure A11). Basin 1 has a volume of about 450,000 $\mathrm{m}^{3}$ (Figure A12a), whereas the other one is only about $10 \%$ of that size (Figure A12b). The spatial distributions of the dams illustrate the dam geometry with highest dam heights at the center of the dam. Additionally, the figures indicate that the raster resolution might not be high enough for a profound calculation of the dam volumes.

Dam Characteristics The second page of the basin fact sheets is visualized (for both dams) in Figure A13. The graphs show distinct differences among the basins with respect to the dam volumes, dam axis lengths, basin volumes, basin areas, the relation of dam volume and basin volume and the shares of well-suited cells in the basins. In contrast, the relations of the basin area to the basin volume and the specific volumes are similar. The dam heights of both basins were chosen based on the values of the objective functions, since the upper limits (basin volume, specific volume, dam height) were not 
reached. Lower dam heights were excluded due to the restriction of the minimum specific volume of $10 \mathrm{~mm}$

Exit Codes The spatial distribution of the exit codes in Figure A14 evaluated the suitability of different river sections for the positioning of retention basins (Table 1). Especially at upstream positions, river points were excluded, because the basin reached the borders $(=10)$, the basin was to small $(=14)$ or the specific volume was to small $(=16)$. The distribution may indicate that the selected extent is not large enough to get the optimal basin position.

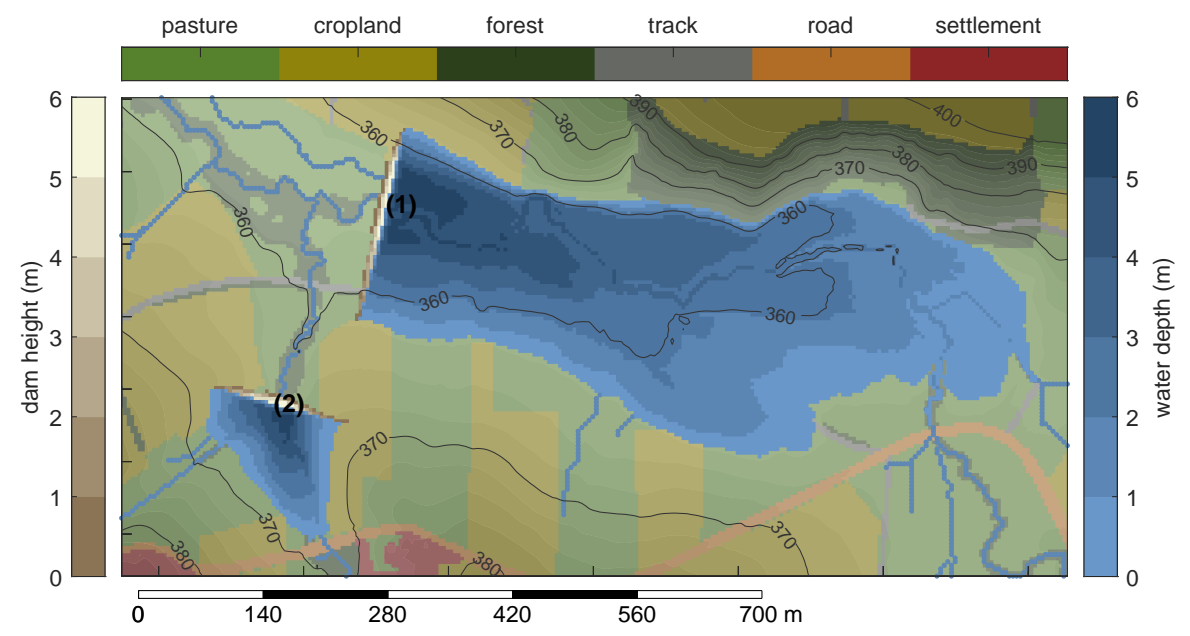

Figure A11. Results of the example dataset: spatial distribution of the dams and basins.
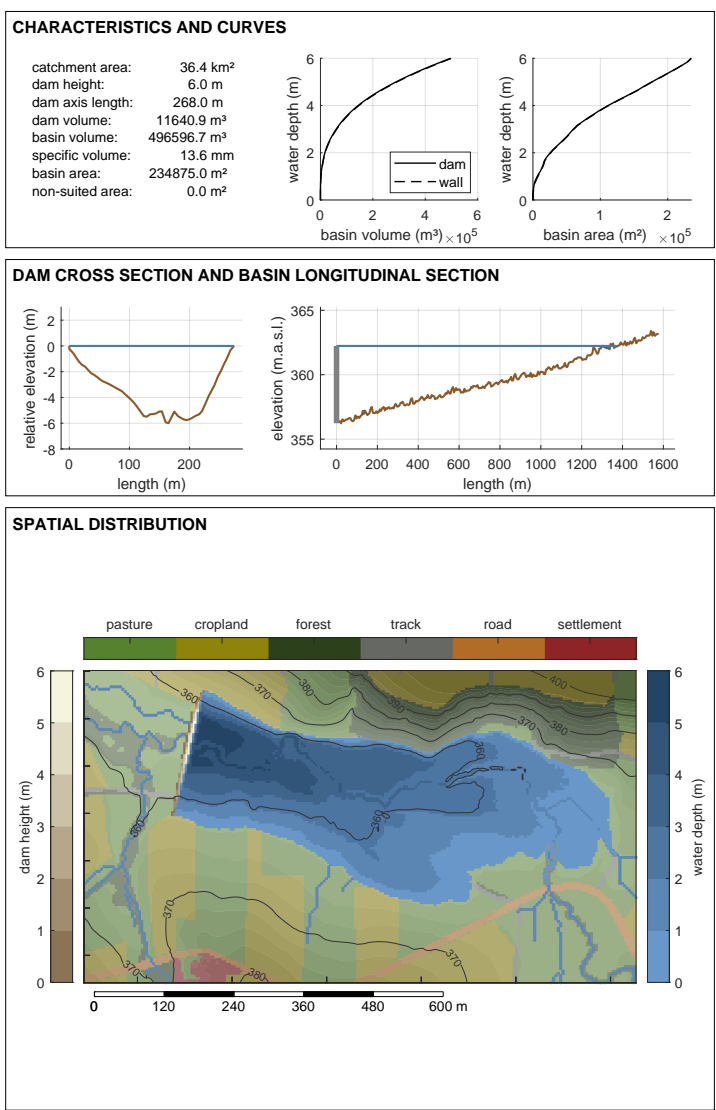

(a) Basin 1
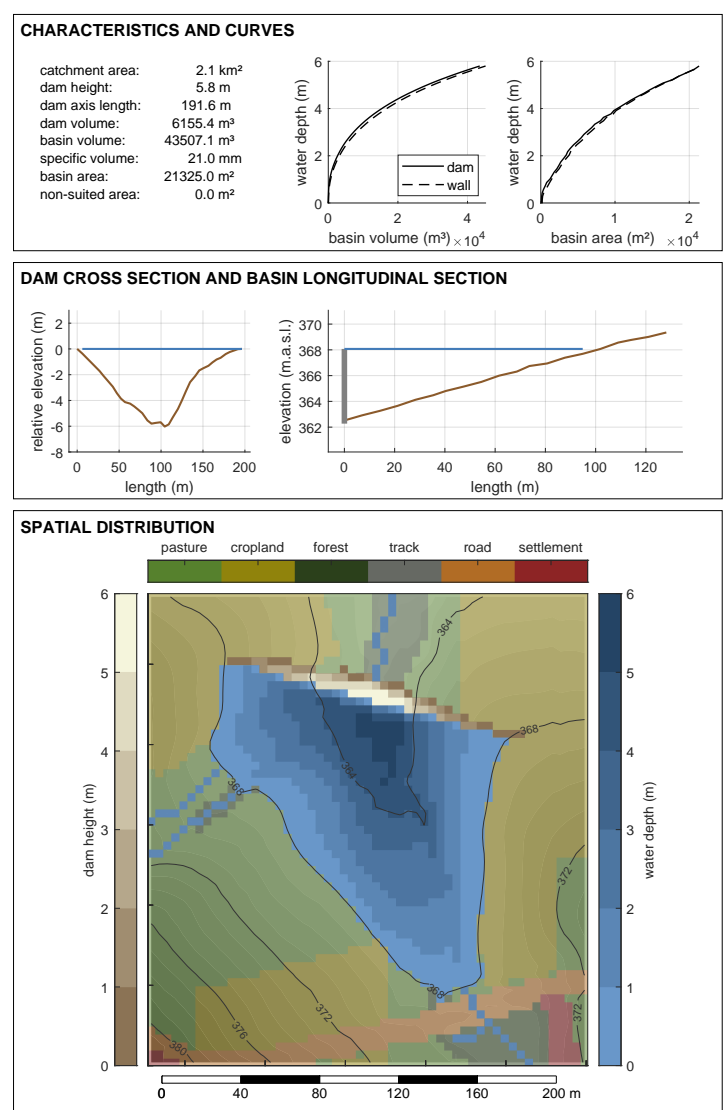

(b) Basin 2.

Figure A12. Fact sheets of the two basins: information on the basin characteristics. 

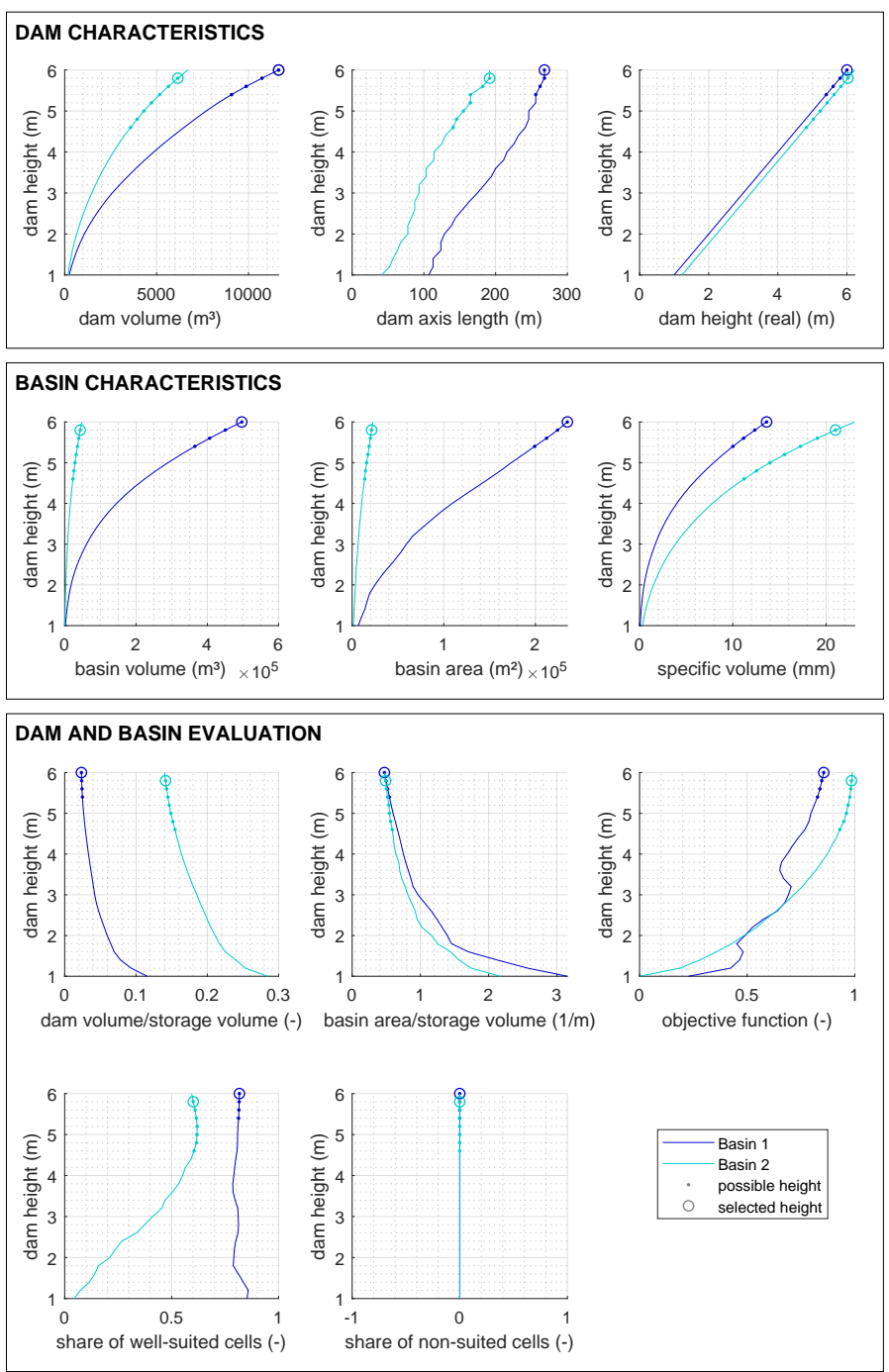

Figure A13. Second page of the fact sheet: comparison of the information on the potential dam heights for both basins.

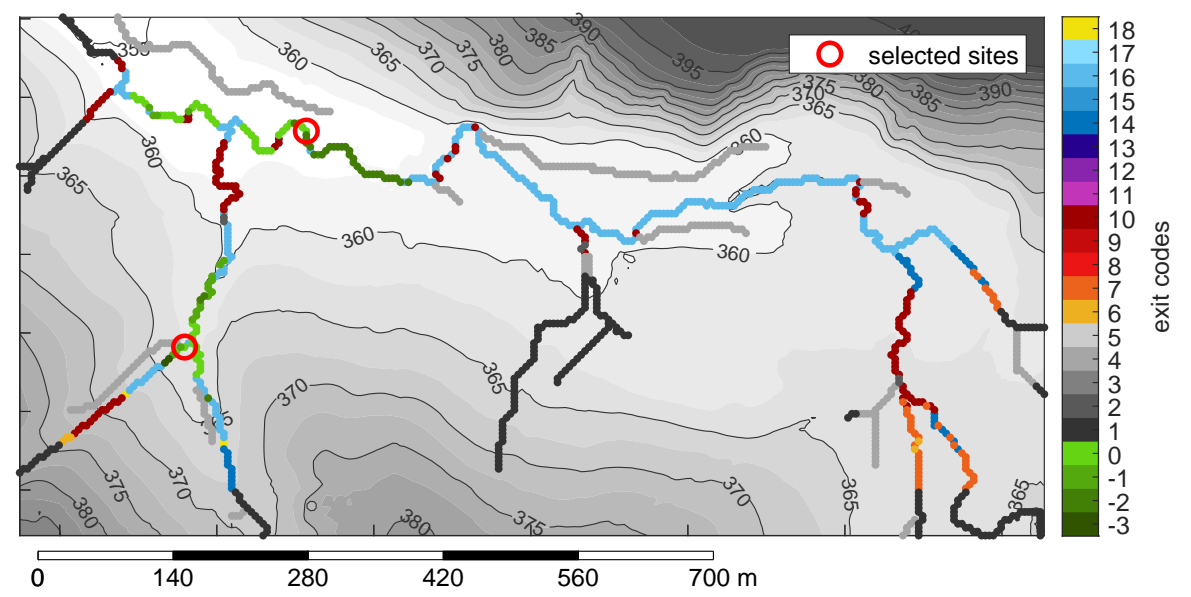

Figure A14. Results of the example dataset: spatial distribution of the river network with exit codes (Table 1). 


\section{References}

1. Rossetto, R.; De Filippis, G.; Borsi, I.; Foglia, L.; Cannata, M.; Criollo, R.; Vázquez-Suñé, E. Integrating free and open source tools and distributed modelling codes in GIS environment for data-based groundwater management. Environ. Model. Softw. 2018, 107, 210-230. [CrossRef]

2. Bittner, D.; Rychlik, A.; Klöffel, T.; Leuteritz, A.; Disse, M.; Chiogna, G. A GIS-based model for simulating the hydrological effects of land use changes on karst systems-The integration of the LuKARS model into FREEWAT. Environ. Model. Softw. 2020, 127, 104682. [CrossRef]

3. Heudorfer, B.; Stahl, K. Comparison of different threshold level methods for drought propagation analysis in Germany. Hydrol. Res. 2017, 48, 1311-1326. [CrossRef]

4. Yang, Q.; Shao, J.; Scholz, M.; Plant, C. Feature selection methods for characterizing and classifying adaptive Sustainable Flood Retention Basins. Water Res. 2011, 45, 993-1004. [CrossRef] [PubMed]

5. Collentine, D.; Futter, M.N. Realising the potential of natural water retention measures in catchment flood management: Trade-offs and matching interests. J. Flood Risk Manag. 2018, 11, 76-84. [CrossRef]

6. Dillon, P.; Stuyfzand, P.; Grischek, T.; Lluria, M.; Pyne, R.D.G.; Jain, R.C.; Bear, J.; Schwarz, J.; Wang, W.; Fernandez, E.; et al. Sixty years of global progress in managed aquifer recharge. Hydrogeol. J. 2019, 27, 1-30. [CrossRef]

7. Baek, C.W.; Lee, J.H.; Paik, K. Optimal location of basin-wide constructed washlands to reduce risk of flooding. Water Environ. J. 2014, 28, 52-62. [CrossRef]

8. Bellu, A.; Fernandes, L.F.S.; Cortes, R.M.; Pacheco, F.A. A framework model for the dimensioning and allocation of a detention basin system: The case of a flood-prone mountainous watershed. J. Hydrol. 2016, 533, 567-580. [CrossRef]

9. Reinhardt, C.; Bölscher, J.; Schulte, A.; Wenzel, R. Decentralised water retention along the river channels in a mesoscale catchment in south-eastern Germany. Phys. Chem. Earth Parts A B C 2011, 36, 309-318. [CrossRef]

10. Teschemacher, S.; Rieger, W. Ereignisabhängige Optimierung dezentraler Kleinrückhaltebecken unter Berücksichtigung von Standort, Retentionsvolumen und Drosselweite. Hydrol. Wasserbewirtsch. 2018, 62, 321-335.

11. Faulkner, J.W.; Steenhuis, T.; van de Giesen, N.; Andreini, M.; Liebe, J.R. Water use and productivity of two small reservoir irrigation schemes in Ghana's Upper East Region. Irrig. Drain. J. Int. Comm. Irrig. Drain. 2008, 57, 151-163. [CrossRef]

12. Massuel, S.; Perrin, J.; Mascre, C.; Mohamed, W.; Boisson, A.; Ahmed, S. Managed aquifer recharge in South India: What to expect from small percolation tanks in hard rock? J. Hydrol. 2014, 512, 157-167. [CrossRef]

13. Perez-Pedini, C.; Limbrunner, J.F.; Vogel, R.M. Optimal location of infiltration-based best management practices for storm water management. J. Water Resour. Plan. Manag. 2005, 131, 441-448. [CrossRef]

14. Nooka Ratnam, K.; Srivastava, Y.K.; Venkateswara Rao, V.; Amminedu, E.; Murthy, K.S.R. Check dam positioning by prioritization of micro-watersheds using SYI model and morphometric analysis-Remote sensing and GIS perspective. J. Indian Soc. Remote Sens. 2005, 33, 25-38. [CrossRef]

15. Fedorov, M.; Badenko, V.; Maslikov, V.; Chusov, A. Site selection for flood detention basins with minimum environmental impact. Procedia Eng. 2016, 165, 1629-1636. [CrossRef]

16. Petheram, C.; Gallant, J.; Read, A. An automated and rapid method for identifying dam wall locations and estimating reservoir yield over large areas. Environ. Model. Softw. 2017, 92, 189-201. [CrossRef]

17. Wimmer, M.; Pfeifer, N.; Hollaus, M. Automatic Detection of Potential Dam Locations in Digital Terrain Models. ISPRS Int. J. Geo-Inf. 2019, 8, 197. [CrossRef]

18. Convertino, M.; Annis, A.; Nardi, F. Information-theoretic portfolio decision model for optimal flood management. Environ. Model. Softw. 2019, 119, 258-274. [CrossRef]

19. Jairaj, P.; Vedula, S. Multireservoir system optimization using fuzzy mathematical programming. Water Resour. Manag. 2000, 14, 457-472. [CrossRef]

20. Rashid, M.U.; Latif, A.; Azmat, M. Optimizing irrigation deficit of multipurpose Cascade reservoirs. Water Resour. Manag. 2018, 32, 1675-1687. [CrossRef]

21. Rahman, M.A.; Rusteberg, B.; Gogu, R.; Ferreira, J.L.; Sauter, M. A new spatial multi-criteria decision support tool for site selection for implementation of managed aquifer recharge. J. Environ. Manag. 2012, 99, 61-75. [CrossRef] [PubMed] 
22. Scanlon, B.R.; Reedy, R.C.; Faunt, C.C.; Pool, D.; Uhlman, K. Enhancing drought resilience with conjunctive use and managed aquifer recharge in California and Arizona. Environ. Res. Lett. 2016, 11, 035013. [CrossRef]

23. Read, A.M.; Gallant, J.C.; Petheram, C. DamSite: An automated method for the regional scale identificatin of dam wall locations. In Hydrology and Water Resources Symposium 2012; Engineers Australia: Barton, Australia, 2012; pp. 1999-2105.

24. Rieger, W.; Teschemacher, S.; Haas, S.; Springer, J.; Disse, M. Multikriterielle Wirksamkeitsanalysen zum dezentralen Hochwasserschutz. Wasserwirtschaft 2017, 107, 56-60. [CrossRef]

25. Esri. ArcMap. 2019. Available online: https://desktop.arcgis.com/de/documentation/ (accessed on 19 December 2019).

26. Bayerische Vermessungsverwaltung. Geländemodell DGM1: Gitterweite: 1 m, 2015. München: Landesamt für Digitalisierung, Breitband und Vermessung. Available online: https:/ /www.ldbv.bayern.de/produkte/ 3dprodukte/gelaende.html (accessed on 19 December 2019).

27. Bayerische Vermessungsverwaltung. Gewässernetz: Grundlage: ATKIS Basis-DLM25, 2014. Augsburg: Bayerisches Landesamt für Umwelt. Available online: https:/ /www.lfu.bayern.de/wasser/ gewaesserverzeichnisse/fachlicher_hintergrund/index.htm (accessed on 19 December 2019).

28. Bayerische Vermessungsverwaltung. Tatsächliche Nutzung der Erdoberfläche: Bestandteil von ALKIS, 2015. München: Landesamt für Digitalisierung, Breitband und Vermessung. Available online: https: / / www.ldbv.bayern.de/produkte/kataster/tat_nutzung.html (accessed on 19 December 2019).

(C) 2020 by the authors. Licensee MDPI, Basel, Switzerland. This article is an open access article distributed under the terms and conditions of the Creative Commons Attribution (CC BY) license (http://creativecommons.org/licenses/by/4.0/). 